\title{
The CJIE1 prophage of Campylobacter jejuni affects protein expression in growth media with and without bile salts
}

\author{
Clifford G Clark ${ }^{1 *}$, Patrick M Chong ${ }^{2}$, Stuart J McCorrister ${ }^{2}$, Philippe Simon ${ }^{3,4}$, Matthew Walker ${ }^{1}$, David M Lee ${ }^{2,5}$, \\ Kimberly Nguy ${ }^{1}$, Keding Cheng ${ }^{2}$, Matthew W Gilmour ${ }^{1}$ and Garrett R Westmacott ${ }^{2}$
}

\begin{abstract}
Background: The presence of Campylobacter jejuni temperate bacteriophages has increasingly been associated with specific biological effects. It has recently been demonstrated that the presence of the prophage CJIE1 is associated with increased adherence and invasion of C. jejuni isolates in cell culture assays.

Results: Quantitative comparative proteomics experiments were undertaken using three closely related isolates with CJIE1 and one isolate without CJE1 to determine whether there was a corresponding difference in protein expression levels. Initial experiments indicated that about $2 \%$ of the total proteins characterized were expressed at different levels in isolates with or without the prophage. Some of these proteins regulated by the presence of CJIE1 were associated with virulence or regulatory functions. Additional experiments were conducted using C. jejuni isolates with and without CJE1 grown on four different media: Mueller Hinton (MH) media containing blood; $\mathrm{MH}$ media containing $0.1 \%$ sodium deoxycholate, which is thought to result in increased expression of virulence proteins; $\mathrm{MH}$ media containing 2.5\% Oxgall; and MHwithout additives. These experiments provided further evidence that CJIE1 affected protein expression, including virulence-associated proteins. They also demonstrated a general bile response involving a majority of the proteome and clearly showed the induction of almost all proteins known to be involved with iron acquisition. The data have been deposited to the ProteomeXchange with identifiers PXD000798, PXD000799, PXD000800, and PXD000801.
\end{abstract}

Conclusion: The presence of the CJIE1 prophage was associated with differences in protein expression levels under different conditions. Further work is required to determine what genes are involved in causing this phenomenon.

Keywords: Campylobacter jejuni, Prophage, Proteomics, iTRAQ, Bile response, Iron acquisition

\section{Background}

Accumulating evidence suggests that $C$. jejuni prophages CJIE1, CJIE2, and CJIE4, like the prophages of other enteric bacteria, can have a profound influence on the virulence and biology of the organism. Expression of prophageencoded DNAses dramatically reduces the rate of natural transformation [1,2], and the presence of homologs of the CJIE1 prophage is associated with increases in adhesion and invasion [3]. In addition to the $d n s$ gene responsible for the production of the extracellular DNAse, proteins

\footnotetext{
* Correspondence: Clifford.Clark@phac-aspc.gc.ca

${ }^{1}$ Enterics Research Section, Bacteriology and Enterics Program, National Microbiology Laboratory, Public Health Agency of Canada, 1015 Arlington St, Winnipeg, Manitoba R3E 3R2, Canada

Full list of author information is available at the end of the article
}

encoded by CJIE1 that could influence infection of hosts or survival in the environment include a putative secreted phospholipase A2 (CJE0229 homolog), a DNA adenine methylase (CJE0220 homolog), a number of hypothetical proteins with unknown functions, and two overlapping novel prophage cargo genes producing proteins provisionally designated ORF10 and ORF11 [4]. We have so far been unable to obtain infectious phage particles by induction of the CJIE1 prophage that would be useful for the creation of isogenic strains, and are not aware that any other groups have been successful either. It would be of interest to determine whether any of these prophage-encoded proteins were actually expressed and whether the presence of the prophage affected expression of other bacterial proteins.

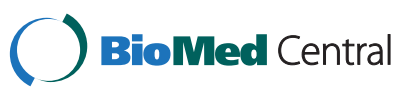

of the article

(c) 2014 Clark et al.; licensee BioMed Central Ltd. This is an Open Access article distributed under the terms of the Creative Commons Attribution License (http://creativecommons.org/licenses/by/2.0), which permits unrestricted use, distribution, and reproduction in any medium, provided the original work is properly credited. 
Most protein identification experiments for $C$. jejuni have utilized one- or two-dimensional gel electrophoresis followed by mass spectroscopy of excised spots to identify expression changes specific peptides or proteins [5-10]. Recent advances in quantitative proteomic characterization include relative protein quantification by stable isotope labelling of proteins or peptides and label-free quantification [11]. Label-free quantitation of peptides/proteins using spectral counting has been used successfully for $E$. coli [12]. A method of stable isotope labelling, isobaric Tags for Relative and Absolute Quantitation (iTRAQ), has been described for quantitation of protein expression levels across multiple samples [13]. iTRAQ labelling has been used successfully for assessing proteome changes in Acinetobacter baumanii [14].

A previous report indicated that, for a subset of the known C. jejuni virulence genes, expression could be induced by growth of the organism on Mueller-Hinton agar containing $0.1 \%$ sodium deoxycholate [15]. In contrast, inclusion of $2.5 \%$ ox-bile in liquid medium significantly inhibited growth of $C$. jejuni and caused changes in protein expression [16] that suggested a specific bile stress response [17], but did not appear to cause discernable up- or down-regulation of virulence proteins.

Previous work in our laboratory indicated that the presence of CJIE1 prophage in the closely related $C$. jejuni isolates 00-2425, 00-2538, and 00-2544 was associated with higher adherence and invasion compared with the closely related isolate 00-2426, which lacked CJIE1 [3]. In the current research reported here, comparative proteomics expression experiments were undertaken in rich medium to determine whether CJIE1 proteins were differentially expressed and whether any changes in protein expression of the host bacterium could be detected. Expression of a small number of proteins, including CJIE1 proteins was detected. Additional experiments were then performed, including growth on bile salts, to determine whether the effects of CJIE1 could be detected in other growth conditions. There was evidence for CJIE1 regulation of protein expression in all growth conditions used. Furthermore, these experiments provide evidence for the existence of a general bile response and a characterization of the response to different levels of iron.

\section{Results}

Differential expression of proteins in isolates with and without the CJIE1 prophage in rich medium, experiment 1

Initial experiments were undertaken to detect any differences in protein expression between the four closely related isolates with (isolates 00-2425, 00-2538, and 002544) and without (isolate 00-2426) the CJIE1 prophage. As this experiment was undertaken before it became possible to perform whole genome sequencing of the isolates, three isolates carrying CJIE1 were compared with one isolate lacking the prophage in order to compensate for any differences among isolates and for consistency with previous work [3]. Mueller-Hinton ( $\mathrm{MH})$ agar + blood, a nutrient-rich medium, was used to grow $C$. jejuni for protein extraction. Scaffold analysis identified a total of 1391 total proteins at a $0.3 \%$ protein false discovery rate (FDR).

Altogether, 22 proteins were differentially expressed at a greater than 1.5 -fold change (log2 change $>0.6$ ) and $P<$ 0.05 in the three isolates carrying CJIE1 compared to the single isolate without CJIE1 (Table 1; Additional file 1). Prophage structural proteins (CJE0226, CJE0227, CJE0246), two phage-associated repressors (CJE0215, signal peptidase associated with PanB), and a prophage-associated hypothetical protein (ORF7), were detected only in isolates carrying CJIE1 (Table 1), indicating that the prophage may have been induced to some extent on rich medium and providing further support indicating that these isolates differ only in the presence of CJIE1 [3,18]. The CJE0215 repressor protein was not detected in all biological replicates, suggesting that this protein may have been expressed at levels close to the threshold of detection in these experiments. Proteins encoded by two CJIE1 cargo genes, ORF 11 and the extracellular DNase (CJE0256), were expressed by the three isolates carrying CJIE1 but were not detected in isolate 00-2426. These results verified that the experimental protocols were capable of detecting differences in protein expression associated with the presence or absence of CJIE1.

Fourteen non-prophage proteins were detected at different levels (differentially expressed) depending on the presence and absence of the prophage in the isolates tested (Table 1). These proteins included two flagellar proteins, two proteins within the capsule locus, the Campylobacter invasion phenotype protein, two proteins associated with acetate metabolism and regulation of the acetate switch, and other proteins having diverse functions (Table 1). Two regions of the chromosome, Cj0685-Cj0689 and CJ1098Cj1102, appeared to be disproportionately represented. Most or all proteins encoded by contiguous genes within each of these two regions showed differential expression depending on the presence or absence of the CJIE1 prophage. Only about $2 \%$ of the proteins detected appeared to be significantly regulated by the presence of the CJIE1 prophage.

PCR using primers internal to six genes (Table S1 in Additional file 2) that were highly down-regulated in isolate 00-2426 (up-regulated in isolates carrying CJIE1) produced amplicons of the correct size, and DNA sequencing confirmed their identity. The observed regulation was therefore not due to absence of the genes. Additional PCR analysis for selected loci was performed using primers that amplified the complete coding sequence of each gene, as 
Table 1 Proteins regulated with $\geq 0.6 \log _{2}$ change in three isolates carrying CJIE1 versus the isolate without CJIE1 when grown on $\mathrm{MH}+10 \%$ sheep blood

\begin{tabular}{|c|c|c|c|c|}
\hline Protein name & GI number & Locus in NCTC11168 & Protein function & $\log _{2}$ change $^{b}$ \\
\hline CJIE1 phage repressor protein CJE0215 & gi|57237226 & Not present & Maintenance of lysogeny & $3.10 \pm 1.27^{*}$ \\
\hline CJIE1 hypothetical protein CJE0246 & gi|315124241 & Not present & CJIE1 prophage capsid protein & $2.95 \pm 0.07^{*}$ \\
\hline CJIE1 00-2425 ORF 11 & gi|313116388 & Not present & Unknown & $2.67 \pm 0.65$ \\
\hline CJIE1 extracellular deoxyribonuclease CJE0256 & gi|57237266 & Not present & Degradation of DNA & $2.3 \pm 0.53$ \\
\hline CJIE1 phage major tail tube protein CJE0226 & gi|315124254 & Not present & Prophage structural protein & $2.20 \pm 0^{*}$ \\
\hline CJIE1 major tail sheath protein CJE0227 & gi|315124253 & Not present & Prophage structural protein & 2.20 (single value) \\
\hline CJIE1 signal peptidase I associated with PanB & gi|315124225 & Not present & Prophage repressor & $1.57 \pm 0.78$ \\
\hline CJIE1 hypothetical protein ICDCCJ07001_659 ORF7 & gi|315124224 & Not present & Unknown & $2.95 \pm 0.35^{*}$ \\
\hline Flagellar protein FlaG & gi|157414828 & Cj0547 & Flagellar protein & $-0.77 \pm 0.76$ \\
\hline Flagellar protein Flis & gi|121612919 & Cj0549 & Flagellin specific chaperone & $-1.00 \pm 0.44$ \\
\hline Invasion phenotype protein CipA & gi|157414972 & Cj0685c & Sugar transferase & $2.97 \pm 0.40$ \\
\hline Phosphate acetyltransferase Pta & gi|121613717 & Cj0688 & Acetate metabolism, regulation & $2.30 \pm 0.26$ \\
\hline Acetate kinase AckA & gi|57236992 & Cj0689 & Acetate metabolism, regulation & $2.00 \pm 0.26$ \\
\hline Integral membrane protein CstA & gi|218562536 & Cj0917c & Carbon starvation protein & $-0.73 \pm 0.42$ \\
\hline Aspartate carbamoyltransferase catalytic subunit PyrB & gi|218562712 & Cj1098 & Pyrimidine biosynthesis & $1.66 \pm 0.10$ \\
\hline Oligoendopeptidase F PepF & gi|218562713 & Cj1099 & Degradation of macromolecules & $1.73 \pm 0.31$ \\
\hline Hypothetical protein CJJ81176_1118 & gi|121613077 & Cj1100 & Unknown & $1.50 \pm 0.44$ \\
\hline ATP-dependent DNA helicase UvrD & gi|121612511 & Cj1101 & DNA helicase & $1.70 \pm 0.35$ \\
\hline Hypothetical protein CJE1504 & gi|57238362 & Cj1305c & Unknown & $-0.93 \pm 0.4$ \\
\hline Hypothetical protein ICDCCJ07001_1249 & gi|315124755 & Cj1305c & Unknown & $-2.70 \pm 0.85^{*}$ \\
\hline Methyltransferase protein & gi|218563030 & Cj1426c & Part of capsule locus & $-1.23 \pm 0.38$ \\
\hline Hypothetical protein Cj1429c & gi|218563033 & Cj1429c & Capsule biosynthesis & $1.73 \pm 1.33$ \\
\hline
\end{tabular}

${ }^{\mathrm{a}} \mathrm{GI}$ numbers were retrieved by the Mascot software used for peptide identification; loci in NCTC 11168 were found by blastp searches by searching the NCBI non-redundant protein database using the protein sequence associated with the Gl number.

${ }^{b}$ Three replicate experiments were done. Some experiments returned values for the protein in only $2 / 3$ experiments; these are marked with a '*'. Otherwise the mean + SD $\log _{2}$ change was calculated using all three values. Experiments in which a protein expression level was identified in only one or three biological replicates are indicated with the term "single value". Positive values indicate that proteins were upregulated in isolates carrying CJIE1 and negative values indicate proteins were downregulated in isolates carrying CJIE1 when compared with isolate 00-2426 lacking the CJIE1 prophage.

well as the region upstream of each gene (Additional file 2: Table S1). No differences were seen between isolate 00-2425 and 00-2426 in DNA sequences upstream of the start sites for the proteins Cj1429c (429 bp upstream sequence obtained), FliS (378 bp), UvrD (149 bp), invasion phenotype protein (391 bp), and methyltransferase protein (146 bp). These results were later confirmed by whole genome sequencing (data not shown).

Whole genome sequence data (unpublished data) demonstrated the presence of differences in homopolymeric tract lengths. One such homopolymeric tract length difference was detected in the gene encoding Cj0685 (CipA) only in isolate $00-2426\left(\mathrm{CJIE1}^{-}\right)$and resulted in truncation of the protein. For the locus encoding protein $\mathrm{Cj1305 \textrm {c } /}$ CJE1505, only isolate 00-2426 contained a homopolymeric tract that would result in expression of the fulllength protein, while the experimentally determined DNA sequences of the other three $\mathrm{CJIE}^{+}$isolates would produce a truncated protein. The Cj1426c locus exhibited the same homopolymeric tract frameshift truncating the protein in all four isolates, while Cj1429 carried the homopolymeric tract frameshift truncating the protein in isolates 00-2425 (CJIE1 $\left.{ }^{+}\right), 00-2544\left(\mathrm{CJIE}^{+}\right)$, and 00-2426 $\left(\mathrm{CJIE1}^{-}\right)$, but not in isolate $00-2538\left(\mathrm{CJIE} 1^{+}\right)$. The loci Cj0549 and Cj1098-1191 were all capable of encoding fulllength proteins in all isolates, but expressed different levels of those proteins in different isolates. Finally, the product of Cj0547, FlaG, was detected in all isolates except 002544. Only the 00-2544 locus had a homopolymeric tract frameshift that would truncate the protein, which appears to have resulted in a loss of expression of this protein.

\section{Comparison of $C$. jejuni on two additional media, $\mathrm{MH}$ and} $\mathrm{MH}+\mathrm{SD}$, demonstrated similar patterns of protein expression, experiment 2

The protein expression patterns detected in the first experiment could have been an artifact of the rich growth medium and of little biological significance. Furthermore, guidelines for proteomics experiments have suggested that, among other things, $C$. jejuni should be grown for 
proteomics experiments on solid medium in the presence of sodium deoxycholate [19]. Additional experiments were therefore undertaken to explore the effect(s) of growth on different media on expression of proteins.

To enable direct comparison of CJIE $1^{+}$and CJIE1 ${ }^{-}$isolates on two different growth media in a 4-plex iTRAQ experiment, isolates 00-2425 and 00-2426 were each grown on Mueller-Hinton agar $(\mathrm{MH})$ and on Mueller-Hinton agar containing $0.1 \%$ sodium deoxycholate $(\mathrm{MH}+\mathrm{SD})$. Compared to $\mathrm{MH}+$ blood, $\mathrm{MH}$ is reduced in nutrients, while growth on $\mathrm{MH}+\mathrm{SD}$ has previously been associated with increased expression of specific virulence-associated proteins [15]. Proteins were obtained from lysed cells, digested, iTRAQ labelled, and subjected to 2D-LC-MS/ MS analysis as described in the Materials and Methods.

Scaffold analysis indicated that 1340 proteins were detected with a $7.8 \%$ protein FDR. After removal of nonprokaryotic proteins and proteins lacking values for all fields there were 1225 proteins used for analysis.

A total of 25 proteins were differentially expressed in these experiments (Table 2; Additional file 3); all had $\mathrm{P}$ values of $<0.05$ in the Permutation test (see Additional file 3) except for hypothetical protein ICDCCJ07001_1249, for which differences were not statistically significant at $75 \%(P=0.20)$. Of the eight CJIE1 prophage-associated proteins differentially expressed during growth on $\mathrm{MH}+$ blood (previous experiment) only two were differentially expressed during growth on $\mathrm{MH}$ and $\mathrm{MH}+\mathrm{SD}$, suggesting there may be less induction of prophage proteins on more nutrient-limited medium. Of the non-prophage proteins differentially expressed during growth on $\mathrm{MH}+$ blood (Table 1), nine were differentially expressed during growth on $\mathrm{MH}$ agar and $\mathrm{MH}+\mathrm{SD}$ agar (see protein names in bold, Table 2). These proteins were in the regions of contiguous genes (Cj0685-Cj0689 and CJ1098Cj1102) and within the capsule locus, as noted in the first set of experiments (Table 1). An additional protein encoded by a gene within the capsule locus, the sugar transferase Cj1421, was also differentially expressed in this set of experiments; there was a suggestion that this may also have been the case in the earlier experiment using $\mathrm{MH}+$ blood, but high variability between replicates precluded drawing any definitive conclusions (data not shown). The other 14 proteins that were clearly differentially expressed when grown on $\mathrm{MH}+/-\mathrm{SD}$ did not exhibit equivalent differential expression when grown on $\mathrm{MH}+$ blood (see Table 2). Similarly, 10 proteins exhibiting differential expression on $\mathrm{MH}+$ blood did not appear to have detectable differences in expression between isolates 00-2425 and 00-2426 when grown on $\mathrm{MH}$ or $\mathrm{MH}+\mathrm{SD}$.

In addition to the proteins described in the previous section, two of the proteins described in this experiment contained homopolymeric sequences. The homopolymeric tract within $\mathrm{Cj} 1421$ was the same length in all four isolates tested, and would result in expression of a fulllength protein. The homopolymeric tract in locus Cj0170 would allow expression of full-length protein in isolates 00-2425 and 00-2538 but would cause truncation of the protein in isolates 00-2426 and 00-2544. Much more Cj0170 protein was detected in isolates 00-2425 and 002538 than in the latter two proteins; it seemed likely that the expression of Cj0170 correlated with the length of the homopolymeric tract and not directly with the presence of the CJIE1 prophage.

A few of the proteins in Table 2 appeared to be expressed differently when isolates were grown on $\mathrm{MH}+\mathrm{SD}$ as compared to $\mathrm{MH}$. For isolate $00-2425$, these proteins include homologs of the CJIE1 ORF11 protein, Cj0073c, Cj0088 (though the data associated with this protein had a high standard deviation about the mean), Cj0685c, Cj0922c, and Cj1101. Similarly, growth of isolate $00-2426$ on $\mathrm{MH}+\mathrm{SD}$ versus $\mathrm{MH}$ resulted in comparatively greater amounts detected, therefore apparently higher expression, of Cj0088, Cj0689, Cj1305, and Cj1429.

\section{Growth of $C$. jejuni on different media revealed different patterns of expression, experiments 3 (using isolate 00-2425) and 4 (using isolate 00-2426)}

A large number of proteins appeared to be differentially regulated depending on whether the culture medium contained $0.1 \%$ sodium deoxycholate or not, rather than on the presence or absence of prophage CJIE1 (see Additional file 3). A different experimental design was therefore used in experiments to further assess these observations and to confirm that proteins that appeared to be expressed at much lower levels in isolate 00-2426 were actually expressed.

We compared protein expression for each isolate (each experiment) after growth on $\mathrm{MH}+$ blood, $\mathrm{MH}$, and $\mathrm{MH}+$ SD. A second bile salt preparation (2.5\% Oxgall) was also included to determine which proteins were involved in a general response to bile. As previously noted [16], incorporation of $2.5 \%$ ox-bile in the $\mathrm{MH}+\mathrm{OX}$ media greatly inhibited the growth of these isolates so that a greater number of culture plates were required to obtain sufficient bacterial cells for protein preparation. The expression levels of proteins from cultures grown on $\mathrm{MH}$ agar were used as the reference against which $\log _{2}$ expression values were calculated. The experimental design used required two separate 4-plex iTRAQ experiments, one with four different media for each isolate used, and was therefore incapable of allowing direct comparison of results from isolate $00-2425\left(\mathrm{CJIE}^{+}\right)$to those of $00-2426\left(\mathrm{CJIE} 1^{-}\right)$ though it was possible to compare changes in expression levels compared with the reference.

When data from the separate experiments were merged using the Scaffold program, there were 1464 proteins identified with a $5.0 \%$ protein FDR. Results were quite 
Table 2 Proteins regulated with $\geq 0.6 \log _{2}$ change in isolate 00-2426 (no CJIE1) compared with isolate 00-2425 (with CJIE1, grown on MH) as reference when isolates were grown on $\mathrm{MH}$ and $\mathrm{MH}+\mathrm{SD}$

\begin{tabular}{|c|c|c|c|c|c|c|}
\hline Protein name $^{a}$ & GI number & $\begin{array}{c}\text { Locus in } \\
\text { NCTC } \\
11168\end{array}$ & $\begin{array}{l}\text { Protein function } \\
\text { or region }\end{array}$ & $\begin{array}{c}\log _{2} \text { change } 00- \\
2425 \mathrm{MH}+\text { SD agar }\end{array}$ & $\begin{array}{c}\log _{2} \text { change } 00- \\
2426 \mathrm{MH} \text { agar }\end{array}$ & $\begin{array}{c}\log _{2} \text { change } 00- \\
2426 \mathrm{MH}+\mathrm{SD} \text { agar }\end{array}$ \\
\hline CJIE1 00-2425 ORF 11 & gi|313116388 & Not present & Unknown & $0.67 \pm 0.40$ & $-2.43 \pm 0.70$ & $-2.13 \pm 1.27$ \\
\hline $\begin{array}{l}\text { CJIE1 signal peptidase I } \\
\text { associated with PanB }\end{array}$ & gi|315124225 & Not present & Prophage repressor & $0.50 \pm 0.20$ & $-3.75 \pm 0.64$ & $-3.15 \pm 0.78$ \\
\hline $\begin{array}{l}\text { Hypothetical protein } \\
\text { CJj81176_0110 }\end{array}$ & gi|121613178 & Cj0073c & Unknown & $0.83 \pm 0.21$ & $0.87 \pm 0.99$ & $1.27 \pm 0.67$ \\
\hline $\begin{array}{l}\text { Iron-sulfur cluster binding } \\
\text { protein }\end{array}$ & gi|121612415 & Cj0074c & Unknown & $0.57 \pm 0.6$ & $0.63 \pm 1.01$ & $1.00 \pm 0.61$ \\
\hline $\begin{array}{l}\text { Anaerobic C4-dicarboxylate } \\
\text { transporter }\end{array}$ & gi|218561769 & Cj0088 & & $1.03 \pm 1.04$ & $1.13 \pm 0.40$ & $2.17 \pm 0.38$ \\
\hline Hypothetical protein Cj0170 & gi|218561850 & Cj0170 & Unknown & $-0.30 \pm 0.10$ & $-2.80 \pm 0.90$ & $-2.97 \pm 0.31$ \\
\hline $\begin{array}{l}\text { Hypothetical protein } \\
\text { CJJ81176_0447 }\end{array}$ & gi|121613189 & Cj0427 & Unknown & $0.33 \pm 1.46$ & $1.33 \pm 1.12$ & $1.07 \pm 1.66$ \\
\hline $\begin{array}{l}\text { Invasion phenotype protein } \\
\text { CipA }\end{array}$ & gi|157414972 & Cj0685c & Sugar transferase & $0.70 \pm 0.20$ & $-2.87 \pm 0.21$ & $-2.43 \pm 0.47$ \\
\hline $\begin{array}{l}\text { Phosphate acetyltransferase } \\
\text { Pta }\end{array}$ & gi|121613717 & Cj0688 & $\begin{array}{l}\text { Acetate metabolism, } \\
\text { regulation }\end{array}$ & $-0.03 \pm 0.21$ & $-2.43 \pm 0.31$ & $-2.67 \pm 0.58$ \\
\hline Acetate kinase AckA & gi|384443065 & Cj0689 & $\begin{array}{l}\text { Acetate metabolism, } \\
\text { regulation }\end{array}$ & $-0.33 \pm 0.64$ & $-3.37 \pm 0.25$ & $-2.70 \pm 1.00$ \\
\hline Oxidoreductase & gi|218562461 & Cj0833c & Oxidoreductase & $-0.10 \pm 0.10$ & $-0.96 \pm 1.76$ & $-1.10 \pm 0.95$ \\
\hline $\begin{array}{l}\text { Ankyrin repeat-containing } \\
\text { periplasmic protein }\end{array}$ & gi|218562462 & Cj0834c & $\begin{array}{l}\text { Mediates protein- } \\
\text { protein interactions }\end{array}$ & $-0.67 \pm 0.25$ & $-1.20 \pm 2.42$ & $-1.60 \pm 1.05$ \\
\hline $\begin{array}{l}\text { Amino acid ABC transporter, } \\
\text { ATP-binding protein PEB1 }\end{array}$ & gi|121612723 & Cj0922C & $\begin{array}{l}\text { Amino-acid ABC } \\
\text { transporter }\end{array}$ & $0.77 \pm 0.21$ & $0.63 \pm 0.68$ & $1.03 \pm 0.45$ \\
\hline $\begin{array}{l}\text { Aspartate } \\
\text { carbamoyltransferase } \\
\text { catalytic subunit PyrB }\end{array}$ & gi|218562712 & Cj1098 & $\begin{array}{l}\text { Pyrimidine } \\
\text { biosynthesis }\end{array}$ & $0.20 \pm 0.35$ & $-1.70 \pm 0.17$ & $-1.57 \pm 0.21$ \\
\hline Oligoendopeptidase F PepF & gi|218562713 & Cj1099 & $\begin{array}{l}\text { Degradation of } \\
\text { macromolecules }\end{array}$ & $-0.20 \pm 0.10$ & $-1.43 \pm 0.32$ & $-1.63 \pm 0.23$ \\
\hline $\begin{array}{l}\text { ATP-dependent DNA helicase } \\
\text { UvrD }\end{array}$ & gi|384448349 & Cj1101 & DNA helicase & $0.73 \pm 0.42$ & $-1.65 \pm 0.21^{*}$ & $-1.23 \pm 0.47$ \\
\hline $\begin{array}{l}\text { Hypothetical protein } \\
\text { ICDCCJ07001_1249 }\end{array}$ & gi|315124755 & Cj1305 & $\begin{array}{l}\text { Part of O-linked } \\
\text { glycosylation locus }\end{array}$ & $-0.35 \pm 0.35^{*}$ & $1.30 \pm 1.56^{*}$ & $2.53 \pm 2.60$ \\
\hline Hypothetical protein Cj1310c & gi|218562921 & Cj1310c & $\begin{array}{l}\text { Part of O-linked } \\
\text { glycosylation locus }\end{array}$ & $-0.23 \pm 0.25$ & $1.33 \pm 1.02$ & $0.87 \pm 0.81$ \\
\hline Motility accessory factor & gi|407942710 & Cj1318 & $\begin{array}{l}\text { Part of O-linked } \\
\text { glycosylation locus }\end{array}$ & $0.03 \pm 0.32$ & $0.93 \pm 0.98$ & $1.00 \pm 0.17$ \\
\hline $\begin{array}{l}\text { Maf7; hypothetical protein } \\
\text { C8J_1258 }\end{array}$ & gi|157415578 & Cj1342C & $\begin{array}{l}\text { Motility accessory } \\
\text { factor }\end{array}$ & $0.20 \pm 0.10$ & $1.57 \pm 0.31$ & $1.87 \pm 0.31$ \\
\hline Sugar transferase & gi|218563025 & Cj1421c & $\begin{array}{l}\text { Part of capsule } \\
\text { locus }\end{array}$ & $0.50 \pm 0.17$ & $0.80 \pm 0.66$ & $1.3 \pm 0.60$ \\
\hline Methyltransferase protein & gi|218563030 & Cj1426c & $\begin{array}{l}\text { Part of capsule } \\
\text { locus }\end{array}$ & $0.57 \pm 0.72$ & $1.13 \pm 0.72$ & $1.03 \pm 0.65$ \\
\hline Hypothetical protein Cj1429c & gi|218563033 & Cj1429c & $\begin{array}{l}\text { Capsule } \\
\text { biosynthesis }\end{array}$ & $0.33 \pm 0.32$ & $-2.50 \pm 0.36$ & $-1.80 \pm 1.25$ \\
\hline Aminotransferase & gi|218563040 & Cj1436c & $\begin{array}{l}\text { Part of capsule } \\
\text { locus }\end{array}$ & $-0.30 \pm 0.30$ & $-1.53 \pm 1.26$ & $-2.03 \pm 0.25$ \\
\hline $\begin{array}{l}\text { Hypothetical protein } \\
\text { CJj81176_1657 }\end{array}$ & gi|121612948 & Cj1666c & $\begin{array}{l}\text { Probable } \\
\text { periplasmic protein }\end{array}$ & $-0.63 \pm 0.46$ & $-0.63 \pm 0.51$ & $-1.43 \pm 0.38$ \\
\hline
\end{tabular}

a Protein names in bold were also detected in previous experiments after growth on $\mathrm{MH}+10 \%$ sheep blood. Some experiments returned values for the protein in only $2 / 3$ experiments; these are marked with $a^{\prime * \prime}$. Other information was the same as described in the footnote to Table 1. 
reproducible across biological replicate experiments; $83 \%$ of proteins were detected in all three replicates (Figure 1A and B). Relative protein expression levels were similar across replicates, and the majority of proteins varied consistently across replicates grown in same media (Figure $1 \mathrm{C}$ and D). A well-defined effect on protein induction was observed between the $\mathrm{MH}+\mathrm{OX}$ and $\mathrm{MH}+\mathrm{SD}$ media when compared with the $\mathrm{MH}$ and $\mathrm{MH}$ media. Both strains also exhibited clear, consistent differences in protein expression when grown in the $\mathrm{MH}+\mathrm{OX}$ and $\mathrm{MH}+\mathrm{SD}$ media compared to the $\mathrm{MH}+$ blood and $\mathrm{MH}$ media, though the patterns of protein expression were somewhat less reproducible in the presence of these bile salts (see Figure).

A number of proteins were expressed at detectable levels in either C. jejuni 00-2425 or in 00-2426, but not both, when results from these four media were compared (Table 3). Whole genome sequence data (not shown) indicated that, other than the CJIE1 loci, the genes coding for these proteins were present in both isolates and, with one exception, did not have SNPs that would completely abrogate expression. The exception was the serine/threonine transporter protein SstT, which had a SNP only in isolate 00-2426 that would result in the expression of a truncated protein (unpublished data).
SstT protein expression was detected in both isolates 00-2425 and 00-2426 (Additional file 4).

Of the 12 proteins detected only in isolate 00-2425, 9 were CJIE1 prophage proteins, an observation consistent with the presence of the prophage only in this isolate. The other three proteins expressed only in isolate 00-2425 were associated with core functions of the bacterium, and PCR analysis indicated that a product could be amplified using primers specific for the gene encoding Cj1620c in both 00-2425 and 00-2426. Proteins uniquely expressed at detectable levels in C. jejuni 00-2426 included 5 hypothetical proteins of unknown function. As before, PCR amplification products were obtained from both 00-2425 and 00-2426 for all non-CJIE1 loci except CJE0735, which was not tested. Together these data suggest that the differential expression of most or all of these proteins was truly due to regulation associated with the presence or absence of the CJIE1 prophage rather than loss of, or interruption within, the genes involved.

Profound differences in protein expression associated with each different media type were noted. A summary of the results from these experiments are shown in Table 4. Expression of $6-8 \%$ of proteins differed between isolates grown on $\mathrm{MH}+$ blood compared with
A

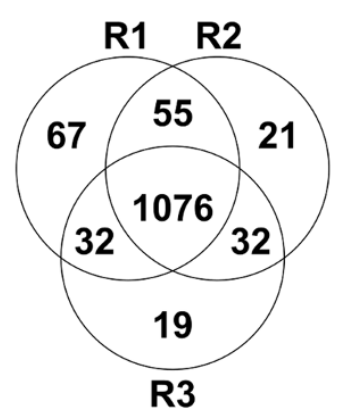

C

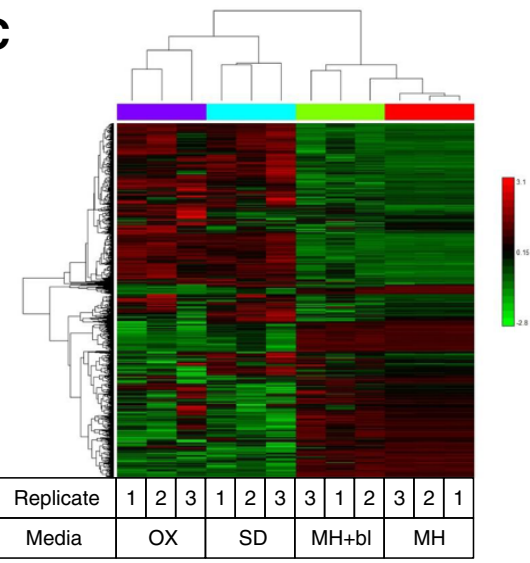

B
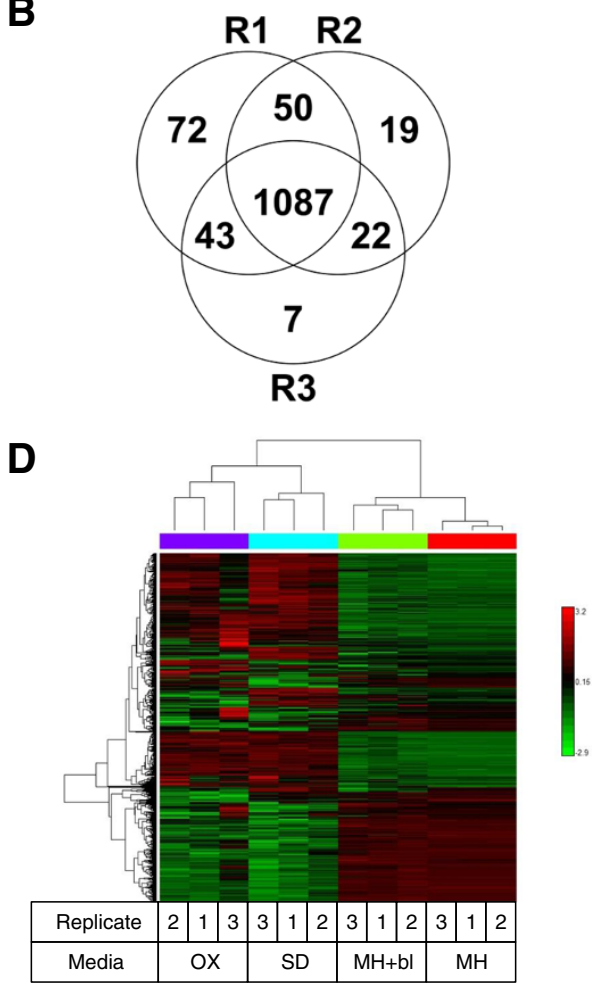

Figure 1 Heat map of proteomic data in experiments comparing growth of isolates on $\mathrm{MH}+$ blood $(\mathrm{MH}+\mathrm{bl}), \mathrm{MH}, \mathrm{MH}+\mathrm{SD}, \mathrm{and} \mathrm{MH}+\mathrm{OX}$. A. C. jejuni 00-2425, showing consistent expression of 1076/1302 proteins (area of overlap) identified in three biological replicate experiments. B. C. jejuni 00-2426 strain, showing consistent expression of 1087/1300 proteins (area of overlap) identified in three biological replicate experiments. Cluster analysis for proteins expressed in isolates 00-2425 (C) and 00-2426 (D). 
Table 3 Proteins detected only in C. jejuni 00-2425 (carrying CJIE1) or in C. jejuni 00-2426 (without CJIE1)

\begin{tabular}{|c|c|c|c|}
\hline \multicolumn{2}{|c|}{ Protein designation } & Protein name & GI Number \\
\hline \multicolumn{4}{|c|}{ Detected only in isolate 00-2425 (carrying CJIE1) } \\
\hline CJIE1 & Prophage indel & 00-2425 hotspot protein ORF11 & gi|313116388 \\
\hline CJIE1 & Prophage & Signal peptidase I prophage repressor & gi|315124225 \\
\hline CJIE1 & Prophage ORF7 & Hypothetical protein ICDCCJ07001_659 & gi|315124224 \\
\hline CJE0269 & Prophage & Bacteriophage DNA transposition protein B, putative & gi|57237279 \\
\hline CJE0256 & Prophage & Extracellular deoxyribonuclease & gi|57237266 \\
\hline CJE0246 & Prophage & Hypothetical protein ICDCCJ07001_677 & gi|315124241 \\
\hline CJE0228 & Prophage & Hypothetical protein ICDCCJ07001_690 & gi|315124252 \\
\hline CJE0226 & Prophage & Phage major tail tube protein & gi|315124254 \\
\hline CJE0215 & Prophage & Phage repressor protein & gi|157414969 \\
\hline Cj1620c & MutY & A/G-specific adenine glycosylase & gi|218563209 \\
\hline Cj1588c & & putative MFS transport protein & gi|218563177 \\
\hline Thauera spp. & & pyruvate phosphate dikinase PEP/pyruvate-binding & gi|217970436 \\
\hline \multicolumn{4}{|c|}{ Detected only in isolate $00-2426$ without CJIE1 } \\
\hline Cj0065c & FolK & 2-amino-4-hydroxy-6-hydroxymethyldihydropteridine pyrophosphokinase & gi|157414379 \\
\hline Cj1731c & & Holliday junction resolvase & gi|121612651 \\
\hline Cj0566 & & Hypothetical protein Cj0566 & gi|218562217 \\
\hline Cj0620 & & Hypothetical protein Cj0620 & gi|218562271 \\
\hline CJE1531 & & Hypothetical protein CJE1531 & gi|57238385 \\
\hline Cj1113 & & Hypothetical protein CJJ81176_1131 & gi|121613282 \\
\hline Cj1193c & & Hypothetical protein CJJ81176_1208 & gi|121613678 \\
\hline CJE0735 & $\| v C$ & Ketol-acid reductoisomerase & gi|152990905 \\
\hline
\end{tabular}

isolates grown on MH medium (Table 4). Much higher proportions of the total proteins exhibited differential regulation when comparing $\mathrm{MH}$ with $\mathrm{MH}+\mathrm{SD}(\sim 72-$ $79 \%)$ and $\mathrm{MH}$ with $\mathrm{MH}+\mathrm{OX}(\sim 69-70 \%)$. Between $5-$ $11 \%$ of proteins appeared to be differentially expressed when $\mathrm{MH}+\mathrm{SD}$ and $\mathrm{MH}+\mathrm{OX}$ were compared. These results are consistent with a fairly specific, targeted response when comparing medium with and without blood; a general stress response to bile salts; and a small number of regulatory effects specific for either $0.1 \%$ sodium deoxycholate or $2.5 \%$ Oxgall. There also appeared to be a limited number of differences in protein expression observed due to the presence of CJIE1 in isolate $00-2425$, detected as differences in the number of proteins differentially expressed when comparing $\mathrm{MH}$ and $\mathrm{MH}+\mathrm{SD}$, and $\mathrm{MH}+\mathrm{SD}$ and SD + OX.

Proteins showed differential expression in isolates with and without CJIE1 when grown on $\mathrm{MH}+\mathrm{SD}$ and $\mathrm{MH}+\mathrm{OX}$ compared with $\mathrm{MH}$

Differential expression was detected for several proteins when isolates were grown on $\mathrm{MH}$ and $\mathrm{MH}+\mathrm{SD}$ media

Table 4 Protein expression showing $\geq \log _{2} 0.6$ change in isolates grown on different media

\begin{tabular}{|c|c|c|c|c|c|c|c|}
\hline \multirow[t]{2}{*}{ Comparison } & \multicolumn{4}{|c|}{ Number of proteins up-regulated } & \multirow{2}{*}{$\begin{array}{l}\text { Total } \\
\text { regulated }\end{array}$} & \multirow{2}{*}{$\begin{array}{c}\text { Total } \\
\text { proteins }\end{array}$} & \multirow{2}{*}{$\begin{array}{c}\% \text { of } \\
\text { total } \\
\text { regulatec }\end{array}$} \\
\hline & In $\mathrm{MH}$ & In $\mathrm{MH}$ & In SD & In OX & & & \\
\hline 00- $2425 \mathrm{MH}+$ blood vs MH & 44 & 70 & & & 114 & 1366 & 8.3 \\
\hline 00- $2426 \mathrm{MH}+$ blood vs MH & 37 & 53 & & & 90 & 1363 & 6.6 \\
\hline 00-2425 MH vs SD & & 426 & 568 & & 994 & 1365 & 72.8 \\
\hline 00-2426 MH vs SD & & 463 & 615 & & 1078 & 1362 & 79.1 \\
\hline 00-2425 MH vs OX & & 426 & & 531 & 957 & 1366 & 70.1 \\
\hline 00-2426 MH vs OX & & 439 & & 503 & 942 & 1362 & 69.2 \\
\hline 00-2425 SD vs OX & & & 124 & 29 & 153 & 1375 & 11.1 \\
\hline 00-2426 SD vs OX & & & 40 & 33 & 73 & 1375 & 5.3 \\
\hline
\end{tabular}


(Additional file 4, an Excel file containing a complete data set describing the third and fourth experiments). Among the proteins more highly up-regulated on $\mathrm{MH}+$ $\mathrm{SD}$ were $\mathrm{CmeA}, \mathrm{CmeB}, \mathrm{CmeC}$, other outer membrane efflux system proteins, the iron-uptake $\mathrm{ABC}$ transporter ATP-binding protein $\mathrm{CfbpC}$, a subset of $30 \mathrm{~S}$ ribosomal proteins, the TlyA hemolysin, the thermonuclease family protein, a number of proteins associated with motility, PEB1 (in $\mathrm{MH}+\mathrm{SD}$ only), and some of the proteins associated with cell wall/membrane/envelope biogenesis. There were also proteins whose expresson was downregulated during growth on $\mathrm{MH}+\mathrm{SD}$ relative to $\mathrm{MH}$, including CiaB, PEB4, catalase, and the AhpC/Tsa family antioxidant protein. Additional proteins exhibiting differential expression in the presence of bile salts can be found in Additional file 4. A few of these proteins appeared to have increased or decreased expression from the reference condition depending on the presence or absence of the CJIE1 prophage.

\section{Bile salts affect the expression of proteins regulated by CJIE1}

Proteins affected by the presence or absence of CJIE1, described above, were also regulated by bile salts. The invasion phenotype protein (CipA) and UvrD were both more highly expressed in both 00-2425 and 00-2426 in the presence of both $0.1 \%$ sodium deoxycholate and 2.5\% Oxgall (Table 5). Hypothetical protein Cj1429 was more highly expressed at $\log _{2}$ values $\geq 0.6$ in isolate 00 2426 in the presence of both bile salt preparations, but in isolate 00-2425 only in the presence of $2.5 \%$ Oxgall. Similarly, the aspartate carbamoyltransferase catalytic subunit was expressed at $\log _{2}$ values $\geq 0.6$ in isolate 00 2426 in the presence of both bile salt preparations but in isolate $00-2425$ only in the presence of $0.1 \%$ sodium deoxycholate. Acetate kinase and oligoendopeptidase $F$ exhibited decreased expression at $\log _{2}$ values $\geq 0.6$ in both isolates but only in the presence of $0.1 \%$ deoxycholate.

Bile salts induce prophages and affect expression of proteins encoded by various CJIE elements

CJIE1 affected expression of some prophage structural proteins and some cargo genes as well. As shown in Additional file 2: Table S2, a slight increase in CJIE1 prophage protein expression occurred when isolate $00-$ 2425 was grown on $\mathrm{MH}+\mathrm{SD}$, while growth on $\mathrm{MH}+$ OX generally resulted in greater changes in CJIE1 structural protein expression (Additional file 2: Table S2). These changes occurred in the absence of significant changes in expression of the CJE0215 repressor protein, and despite the increased expression of the second CJIE1 repressor (signal peptidase I) located near the gene encoding PanG in the 00-2425 genome [4]. Expression of ORF11, the unique protein product of a gene carried within CJIE1, was also increased in the presence of both bile salts. In contrast, inclusion of bile salts in the growth medium resulted in a $2-3$ fold decrease in expression of the extracellular deoxyribonuclease carried by CJIE1.

There was evidence that the expression of proteins encoded by CJIE4 was also affected by bile salts (Additional file 2: Table S2). In this case, growth of both 00-2425 and $00-2426$ on medium containing bile salts resulted in a $\sim 3-5$ fold reduction in expression of one of the prophage repressor proteins (CJE1429), with concomitant increases in the expression of various prophage structural or functional proteins. In contrast, expression of the second prophage repressor carried by CJIE4 (CJIE1440) did not

Table 5 Effect of media differing in iron concentration and inclusion of bile salts on expression of consensus proteins differentially regulated by the presence or absence of CJIE1 in initial experiments

\begin{tabular}{|c|c|c|c|c|c|c|c|}
\hline \multirow{3}{*}{ Protein } & \multirow{3}{*}{ COG } & \multirow{3}{*}{ Gl number } & \multirow{3}{*}{ Locus in NCTC 11168} & \multicolumn{4}{|c|}{$\log _{2}$ change } \\
\hline & & & & \multicolumn{2}{|c|}{$0.1 \%$ sodium deoxycholate } & \multicolumn{2}{|c|}{$2.5 \%$ Oxgall } \\
\hline & & & & $00-2425$ & $00-2426$ & $00-2425$ & $00-2426$ \\
\hline Invasion phenotype protein CipA & $\mathrm{R}$ & gi|157414972 & Cj0685c & $1.17 \pm 0.30$ & $1.57 \pm 0.35$ & $1.13 \pm 0.46$ & $1.20 \pm 0.66$ \\
\hline phosphate acetyltransferase Pta & $\mathrm{R}$ & gi|121613717 & Cj0688 & $0.07 \pm 0.30$ & $1.10(n=1)$ & $-0.93 \pm 0.21$ & $1.90(n=1)$ \\
\hline Acetate kinase AckA & C & gi|57236992 & Cj0689 & $-1.27 \pm 0.10$ & $-1.00 \pm 0.60$ & $-0.57 \pm 0.50$ & $-0.50 \pm 0.36$ \\
\hline $\begin{array}{l}\text { Aspartate carbamoyltransferase } \\
\text { catalytic subunit PyrB }\end{array}$ & $\mathrm{F}$ & gi|218562712 & Cj1098 & $0.80 \pm 0.30$ & $1.00 \pm 0.20$ & $0.50 \pm 0.40$ & $0.73 \pm 0.25$ \\
\hline Oligoendopeptidase F PepF & E & gi|218562713 & Cj1099 & $-0.87 \pm 0.20$ & $-0.90 \pm 0.17$ & $-0.03 \pm 0.06$ & $-0.13 \pm 0.23$ \\
\hline ATP-dependent DNA helicase UvrD & L & gi|121612511 & Cj1101 & $1.20 \pm 0.30$ & $1.40 \pm 0.17$ & $1.40 \pm 0.36$ & $1.40 \pm 0.10$ \\
\hline Hypothetical protein Cj1429c & S & gi|218563033 & Cj1429c & $0.33 \pm 0.40$ & $1.45 \pm 0.49$ & $1.13 \pm 0.25$ & $2.5 \pm 0$ \\
\hline Methyltransferase protein & & gi|218563030 & Cj1426c & $0.43 \pm 0.30$ & $0.97 \pm 0.21$ & $0.23 \pm 0.40$ & $0.33 \pm 0.70$ \\
\hline
\end{tabular}

Expression of proteins on $\mathrm{MH}+$ blood was set as the reference separately for isolates $00-2425$ and $00-2426$ against which fold change on each of the different growth media was calculated for each isolate.

COGs, [C] Energy production and conversion; [E] Amino acid transport and metabolism; [F] Nucleotide transport and metabolism; [K] Transcription; [L] Replication, recombination, and repair; [Q] Secondary metabolites biosynthesis, transport and catabolism; [R] General function prediction only; [S] Function unknown. 
change much under different growth conditions. Increases in the expression of CJIE4 prophage structural proteins (integrase recombinase, HK97 family major capsid protein) suggested concomitant induction of the prophage in the presence of bile salts. Proteins encoded by two genes in an indel that differed among different strains (C)E1440 and CJE1441, manuscript in preparation) had decreased expression in the presence of bile salts. RloG (CJE1430) was slightly down-regulated $\left(\log ^{2}\right.$ change $\left.=-0.67\right)$ only in the presence of $0.1 \%$ sodium deoxycholate.

Proteins carried by two other integrated elements were expressed in these experiments (Additional file 2: Table S2). A CJIE3 cytochrome $C$ family protein was down-regulated in the presence of bile salts, slightly less so when CJIE1 was present. Three CJIE3 proteins were annotated as having an association with branched chain amino acid transport. Expression of the ATP-binding protein did not change a great deal in the presence of bile salts, while expression of the putative permease protein was increased somewhat (Additional file 2: Table S2). The presence of CJIE1 appeared to have little effect on expression of these proteins. In contrast, the periplasmic amino acid-binding protein was strongly down-regulated in the presence of both bile salts. Only one CJIE2 hypothetical protein appeared to be expressed (Additional file 2: Table S2), and levels of this protein were increased by the presence of bile salts.

These data indicate that CJIE prophages may have been induced upon growth in bile salts. Many prophage cargo genes were expressed; differential carriage of these cargo genes could lead to differences in the biology of the host bacterium.

\section{Bile salts affected expression of selected virulence- associated proteins}

The genes and proteins associated with virulence and pathogenesis of $C$. jejuni have been reviewed recently [20]; a subset of possible virulence genes was selected from the total for further analysis. Comparative protein expression data were reviewed to determine the effects of the CJIE1 prophage and different growth media on expression of a subset of these proteins (Additional file 2: Table S3; Additional file 4).

Proteins involved in capsule polysaccharide synthesis and transport (COG class $\mathrm{M}$ ) were all more highly expressed when isolates were grown on medium containing bile salts. The one exception was the capsular polysaccharide transport protein, which only showed increased expression in the presence of $0.1 \%$ sodium deoxycholate and not in 2.5\% Oxgall. Sialic acid synthase expression was decreased in the presence of bile salts.

Growth on medium containing bile salts resulted in increased expression of flagellin (both sources identified), the flagellar basal rod modification protein, the flagellar biosynthesis regulator FlhA (greater change in expression compared to reference in $0.1 \%$ deoxycholate compared with $2.5 \%$ Oxgall), and the flagellar biosynthesis regulator FlhF (Additional file 2: Table S3). Many other flagellar structural proteins were also expressed at higher levels in the presence of bile salts (Additional file 4). Bile salts decreased the expression of $\mathrm{FlaC}$, the flagellar biosynthesis sigma factor, the flagellar basal rod modification protein, the flagellin modification protein $\mathrm{A}$, and the CheY chemotaxis protein (Additional file 2: Table S3) as well as flagellar assembly proteins, two basal body proteins, the flagellar capping protein, and 2/3 flagellar motor switch proteins (Additional file 4). There was a large difference in expression of the flagellar basal rod modification protein compared with the reference state in the presence and absence of the CJIE1 prophage. Expression of the flagellin modification protein PseA was also decreased, but to a greater degree in the presence of $0.1 \%$ deoxycholate in the culture medium than of $2.5 \%$ Oxgall (Additional file 2: Table S3).

Effector proteins associated with $C$. jejuni pathogenesis also showed changes in expression in the presence of bile salts. Expression of both $\mathrm{CiaB}$ and PEB1 was much lower in the presence of bile salts (Additional file 2: Table S3), as was the expression of $\mathrm{FlaC}$ and all subunits of cytolethal distending toxins, especially subunits $B$ and C. However, expression of the TlyA hemolysin and a flippase involved in N-linked glycosylation was increased in the presence of bile salts.

Expression of a number of regulatory proteins was also affected by growth conditions. The FliA flagellar biosynthesis sigma factor, the DnaK suppressor protein, and the GroES co-chaperonin were all expressed at much lower levels in the presence of bile salts than in reference conditions (growth on $\mathrm{MH}$ ), while the Sigma 54-associated transcriptional regulator and DnaJ were expressed at higher levels. GroEL expression was reduced in the presence of $0.1 \%$ deoxycholate, but elevated somewhat when grown on medium containing $2.5 \%$ Oxgall; in both cases, these effects were less apparent in isolate 00-2425 carrying CJIE1.

While the levels of all virulence-associated proteins were affected to a greater or lesser degree by the presence of bile salts, only a few - most strikingly CiaB, DnaK, PEB1A, and PseA (when grown on $\mathrm{MH}+\mathrm{SD}$ ), and the flagellar basal rod modification protein (when grown on both media containing bile salts) - also appeared to be regulated by the presence of CJIE1.

\section{Growth of bacteria on medium without blood induces proteins involved in iron acquisition and oxidative stress responses}

As seen in Table 4, a minority of proteins were differentially expressed during growth on $\mathrm{MH}+$ blood and $\mathrm{MH}$. Details of these expression differences are shown in Table 6 for 99 proteins. Of the proteins regulated by iron levels 
Table 6 C. jejuni proteins responding to decreased iron concentration assessed by comparing protein expression after growth on $\mathrm{MH}+$ blood and on $\mathrm{MH}$ medium

\begin{tabular}{|c|c|c|c|c|}
\hline \multirow[t]{2}{*}{ Protein } & \multirow{2}{*}{$\begin{array}{l}\text { Locus in } \\
\text { NCTC11168 }\end{array}$} & \multirow[t]{2}{*}{ Gl number } & \multicolumn{2}{|c|}{$\log _{2}$ change in $\mathrm{MH}$ medium } \\
\hline & & & $00-2425$ & $00-2426$ \\
\hline \multicolumn{5}{|l|}{ Iron acquisition } \\
\hline Iron-uptake $\mathrm{ABC}$ transporter ATP-binding protein $\mathrm{CfbpC}$, putative & Cj0173c & gi|218561852 & $1.27 \pm 0.75$ & $1.10 \pm 0.53$ \\
\hline Iron $\mathrm{ABC}$ transporter, permease $\mathrm{CfbpB}$, putative & Cj0174c & gi|121612175 & $0.80 \pm 0.71$ & $0.90 \pm 0$ \\
\hline Iron-uptake $\mathrm{ABC}$ transporter, periplasmic iron-binding protein $\mathrm{CfbpA}$, putative & Cj0175c & gi|218561854 & $2.00 \pm 1.30$ & $1.97 \pm 1.27$ \\
\hline Iron transport protein, putative & Cj0177 & gi|218561856 & $3.30 \pm 0.17$ & $2.73 \pm 1.05$ \\
\hline TonB-denpendent outer membrane receptor, putative & Cj0178 & gi|218561857 & $2.70 \pm 0.56$ & $2.97 \pm 0.29$ \\
\hline Biopolymer transport ExbB protein, TonB transport system & Cj0179 & gi|218561858 & $3.03 \pm 0.32$ & $3.37 \pm 1.61$ \\
\hline Periplasmic TonB transport protein & Cj0753c & gi|315124276 & 3.5 (single value) & 3.5 (single value) \\
\hline Ferric receptor CfrA & Cj0755 & gi|57237601 & $2.37 \pm 0.15$ & $2.23 \pm 0.81$ \\
\hline Enterochelin uptake ATP-binding protein CeuD & Cj1354 & gi|218562963 & $2.00 \pm 1.06$ & $2.00 \pm 0.56$ \\
\hline Enterochelin $\mathrm{ABC}$ transporter, periplasmic enterochelin-binding protein CeuE & Cj1355 & gi|121612138 & $1.80 \pm 0.66$ & $1.40 \pm 0.26$ \\
\hline Periplasmic protein P19 & Cj1659 & gi|157415879 & $1.97 \pm 1.50$ & $2.10 \pm 1.04$ \\
\hline Iron permease, putative & Cj1658 & gi|218563246 & $1.97 \pm 1.04$ & $1.70 \pm 1.01$ \\
\hline Heme iron utilization protein, putative & Cj1613c & gi|121612296 & $3.60 \pm 0.95$ & $3.70 \pm 0.5$ \\
\hline TonB-dependent heme receptor ChuA & Cj1614 & gi|57238627 & $3.35 \pm 0.35$ & $4.20 \pm 0$ \\
\hline TonB-dependent heme receptor ChuA & Cj1614 & gi|157415833 & $1.80 \pm 0.70$ & $1.73 \pm 0.87$ \\
\hline TonB-dependent heme receptor ChuA & Cj1614 & gi|121613006 & $1.20 \pm 0.56$ & $0.33 \pm 0.64$ \\
\hline Hemin $A B C$ transporter, permease protein, putative ChuB & Cj1615 & gi|153951720 & $3.17 \pm 0.55$ & $2.93 \pm 1.19$ \\
\hline Hemin uptake system ATP-binding protein ChuC, putative & Cj1616 & gi|218563205 & $2.97 \pm 0.74$ & $3.07 \pm 0.50$ \\
\hline Hemin uptake system periplasmic hemin-binding protein, putative & Cj1617 & gi|218563206 & $2.83 \pm 0.59$ & $2.53 \pm 0.42$ \\
\hline Biopolymer transport ExbD protein, TonB transport system & Cj1629 & gi|153952038 & $1.63 \pm 0.81$ & $1.57 \pm 0.49$ \\
\hline Integral membrane protein, putative & Cj1660 & gi|218563248 & $1.27 \pm 0.81$ & $1.5 \pm 0.79$ \\
\hline ABC transporter permease, putative & Cj1661 & gi|218563249 & $1.67 \pm 0.97$ & $1.57 \pm 0.67$ \\
\hline Integral membrane protein, putative & Cj1662 & gi|218563250 & $1.93 \pm 1.15$ & $1.60 \pm 0.87$ \\
\hline ABC transporter ATP-binding protein & Cj1663 & gi|157415883 & $1.53 \pm 0.80$ & $1.53 \pm 0.51$ \\
\hline \multicolumn{5}{|l|}{ Oxidative stress } \\
\hline Thioredoxin reductase & Cj0146c & gi|218561827 & $0.93 \pm 0.47$ & $0.87 \pm 0.5$ \\
\hline Antioxidant, AhpC/Tsa family & Cj0334 & gi|157414631 & $0.97 \pm 0.32$ & $0.70 \pm 0.20$ \\
\hline Catalase & Cj1385 & gi|121612952 & $3.37 \pm 0.23$ & $2.80 \pm 0.56$ \\
\hline Thioredoxin-like protein & Cj1664 & gi|121613144 & $1.23 \pm 0.91$ & $1.27 \pm 1.08$ \\
\hline \multicolumn{5}{|l|}{ Anthranilate synthesis } \\
\hline Anthranilate synthase component I & Cj0345 & gi|121612335 & $0.80 \pm 0.75$ & $0.87 \pm 0.71$ \\
\hline Anthranilate synthase component II & Cj0346 & gi|121612640 & $0.67 \pm 0.60$ & $0.60 \pm 0.46$ \\
\hline N-(5'phosphoribosyl)anthranilate isomerase & Cj0347 & gi|157414644 & $1.00 \pm 0.53$ & $0.83 \pm 0.65$ \\
\hline \multicolumn{5}{|l|}{ Chemotaxis } \\
\hline Methyl-accepting chemotaxis protein & Cj1189c & gi|121613242 & $0.70 \pm 1.10$ & $0.07 \pm 0.06$ \\
\hline Methyl-accepting chemotaxis protein & Cj1506c & gi|121613017 & $2.0 \pm 1.31$ & $3.23 \pm 2.40$ \\
\hline \multicolumn{5}{|l|}{ Methionine biosynthesis } \\
\hline 5-methyltetrahydropteroyltriglutamate-homocysteine methyltransferase MetE & Cj1201 & gi|157415465 & $0.50 \pm 0.35$ & $1.20 \pm 0.26$ \\
\hline Homoserine O-succinyltransferase MetA & Cj1726c & gi|121613233 & $0.80 \pm 0.35$ & $1.53 \pm 0.55$ \\
\hline Homoserine O-acetyltransferase MetB & Cj1727c & gi|315125108 & $1.27 \pm 0.57$ & $1.93 \pm 0.9$ \\
\hline
\end{tabular}


Table 6 C. jejuni proteins responding to decreased iron concentration assessed by comparing protein expression after growth on MH + blood and on MH medium (Continued)

\begin{tabular}{|c|c|c|c|c|}
\hline \multicolumn{5}{|l|}{ Molybdate transport } \\
\hline Molybdate transport system ATP-binding protein & Cj0300c & gi|157414597 & $0.67 \pm 0.15$ & $0.77 \pm 0.25$ \\
\hline Hypothetical protein C8J_0279 molybdenum-pterin-binding protein & Cj0302 & gi|157414599 & 0.30 (single value) & $0.67 \pm 0.21$ \\
\hline Molybdate transport system substrate-binding protein & Cj0303 & gi|157414600 & $0.83 \pm 0.75$ & $0.77 \pm 0.25$ \\
\hline \multicolumn{5}{|l|}{ Hypothetical proteins } \\
\hline Hypothetical protein C8J_0062 & Cj0069 & gi|157414383 & $-0.63 \pm 0.06$ & $-0.60 \pm 0.17$ \\
\hline Hypothetical protein CJJ81176_0110 & Cj0073c & gi|121613178 & $-0.93 \pm 0.68$ & $-0.57 \pm 0.35$ \\
\hline Hypothetical protein C8J_0189 & Cj0200c & gi|157414509 & $0.67 \pm 0.81$ & $0.80 \pm 0.78$ \\
\hline Hypothetical protein Cj0427 & Cj0427 & gi|218562085 & $-1.47 \pm 0.67$ & $0.07 \pm 0.58$ \\
\hline Hypothetical protein CJJ81176_0676 & Cj0648 & gi|121613289 & $0.70 \pm 0.28$ & $0.50 \pm 0.36$ \\
\hline Hypothetical protein C8J_1185 & Cj1242 & gi|157415505 & -0.60 (single value) & $-1.10 \pm 0.71$ \\
\hline Hypothetical protein C8J_1529 & Cj1627c & gi|157415847 & $0.60 \pm 0.20$ & $0.50 \pm 0.61$ \\
\hline Hypothetical protein CJJ81176_1628 & Cj1637c & gi|121613390 & $-0.33 \pm 0.15$ & $-0.73 \pm 0.35$ \\
\hline Hypothetical protein C8J_1561 & Cj1659 & gi|157415879 & $1.97 \pm 1.50$ & $2.10 \pm 1.04$ \\
\hline Hypothetical protein CJE0598 CJIE2 prophage & not present & gi|57238304 & $1.10 \pm 0.28$ & $0.77 \pm 0.40$ \\
\hline Hypothetical protein CXIVA_22050 & not present & gi|339443269 & $0.67 \pm 0.57$ & $0.50 \pm 0.53$ \\
\hline \multicolumn{5}{|l|}{ Transporters } \\
\hline Sodium/dicarboxylate symporter & Cj0025c & gi|121612756 & $0.80 \pm 0.66$ & $0.40 \pm 0.44$ \\
\hline Anaerobic C4-dicarboxylate transporter & Cj0088 & gi|218561769 & $-1.10 \pm 0.61$ & $-0.63 \pm 0.23$ \\
\hline OPT family oligopeptide transporter & Cj0204 & gi|121613125 & $0.73 \pm 0.21$ & $0.50 \pm 0.17$ \\
\hline \multicolumn{5}{|l|}{ Other function or unknown function } \\
\hline Non-haem iron protein & Cj0012c & gi|218561705 & $-0.83 \pm 0.61$ & $-0.77 \pm 0.64$ \\
\hline Cytochrome c family protein & Cj0037c & gi|121612292 & $0.93 \pm 0.21$ & $1.03 \pm 0.35$ \\
\hline Aspartate ammonia-lyase & Cj0087 & gi|157414400 & $-1.10 \pm 0.50$ & $-1.1 \pm 0.40$ \\
\hline Periplasmic protein, putative & Cj0093 & gi|218561774 & $0.80 \pm 0.53$ & $0.80 \pm 0.56$ \\
\hline Superoxide dismutase, Fe & Cj0169 & gi|157414485 & $-1.23 \pm 0.84$ & $-1.20 \pm 1.47$ \\
\hline Superoxide dismutase, Fe & Cj0169 & gi|153951398 & $-3.70 \pm 2.95$ & $-0.93 \pm 0.97$ \\
\hline Integral membrane protein & Cj0236c & gi|153952171 & $0.53 \pm 0.75$ & $0.97 \pm 0.76$ \\
\hline Chemotaxis histidine kinase & Cj0284C & gi|218561946 & $-0.83 \pm 0.61$ & $-0.53 \pm 0.42$ \\
\hline Ferredoxin $4 \mathrm{Fe}-4 \mathrm{~S}$ & Cj0333c & gi|121612302 & $-1.10 \pm 0.89$ & $0.53 \pm 0.15$ \\
\hline Tryptophan synthase subunit alpha & Cj0349 & gi|121613100 & $0.67 \pm 0.47$ & $0.80 \pm 0.56$ \\
\hline Cytochrome c551 peroxidase & Cj0358 & gi|121612870 & $-0.67 \pm 0.55$ & $0.50 \pm 0.17$ \\
\hline Putative integral membrane protein & Cj0421c & gi|218562079 & $1.00 \pm 0.71$ & $0.73 \pm 0.12$ \\
\hline Putative periplasmic protein & Cj0425 & gi|218562083 & 1.70 (single value) & 1.10 (single value) \\
\hline Succinate dehydrogenase flavoprotein subunit & Cj0437 & gi|218562095 & $-0.70 \pm 0.44$ & $-0.6 \pm 0.87$ \\
\hline DNA polymerase III subunit epsilon & Cj0452 & gi|218562107 & $-0.23 \pm 0.21$ & $-0.67 \pm 0.31$ \\
\hline Thiamine biosynthesis protein ThiC & Cj0453 & gi|121613325 & $-2.23 \pm 0.38$ & $-1.83 \pm 0.32$ \\
\hline ATP-dependent chaperone protein ClpB & Cj0509c & gi|121613623 & $-0.33 \pm 0.15$ & $-0.67 \pm 0.15$ \\
\hline 2-oxoglutarate-acceptor oxidoreductase subunit OorD & Cj0535 & gi|157414816 & $-0.87 \pm 0.55$ & $0.63 \pm 0.66$ \\
\hline 2-oxoglutarate-acceptor oxidoreductase subunit OorA & Cj0536 & gi|157414817 & $-0.73 \pm 0.32$ & $-0.67 \pm 0.15$ \\
\hline Aminohydrolase family protein, putative & Cj0556 & gi|218562208 & $0.90 \pm 0.57$ & $1.13 \pm 0.71$ \\
\hline Quinol dehydrogenase membrane component $\mathrm{NapH}$ & Cj0782 & gi|121612888 & $-0.67 \pm 0.49$ & $-0.55 \pm 0.35$ \\
\hline Bifunctional aconitate hydratase 2/2-methylisocitrate dehydratase & Cj0835c & gi|218562463 & $-1.00 \pm 0.26$ & $-0.93 \pm 0.59$ \\
\hline Thermonuclease family protein & Cj0979c & gi|121612563 & $-0.83 \pm 0.38$ & $-0.73 \pm 0.68$ \\
\hline
\end{tabular}


Table 6 C. jejuni proteins responding to decreased iron concentration assessed by comparing protein expression after growth on MH + blood and on MH medium (Continued)

\begin{tabular}{|c|c|c|c|c|}
\hline Amino acid transporter, periplasmic solute-binding protein, putative & Cj0982C & gi|218562598 & $1.03 \pm 0.38$ & $0.77 \pm 0.4$ \\
\hline Arginyl-tRNA-protein transferase & Cj1035c & gi|121613462 & $-0.73 \pm 0.29$ & $-0.60 \pm 0.26$ \\
\hline Flippase & Cj1130c & gi|218562744 & $-0.27 \pm 0.38$ & $-0.67 \pm 0.42$ \\
\hline Cytochrome c553 & Cj1153 & gi|157415419 & $-0.77 \pm 0.25$ & $-0.53 \pm 0.38$ \\
\hline Cyclopropane fatty acid biosynthesis & Cj1183c & gi|57238055 & $1.07 \pm 0.67$ & $0.73 \pm 0.32$ \\
\hline NLPA family lipoprotein, putative & Cj1200 & gi|218562812 & $0.47 \pm 0.83$ & $1.20 \pm 0.56$ \\
\hline Hemerythrin family non-heme iron protein & Cj1224 & gi|121612625 & $-0.73 \pm 0.25$ & $-0.07 \pm 0.21$ \\
\hline Quinone-reactive Ni/Fe-hydrogenase, small subunit & Cj1267c & gi|157415531 & $-0.63 \pm 0.46$ & $-0.57 \pm 0.21$ \\
\hline Endoribonuclease L-PSP, putative & Cj1388 & gi|218562997 & $0.77 \pm 0.21$ & $0.40 \pm 0.36$ \\
\hline Putative Ni/Fe-hydrogenase small subunit & Cj1399c & gi|218563003 & $0.73 \pm 0.31$ & $0.57 \pm 0.15$ \\
\hline Hypothetical protein C8J_1356 ATP/GTP-binding protein & Cj1450 & gi|157415675 & $-0.87 \pm 0.38$ & $-0.80 \pm 0.46$ \\
\hline Transformation system protein CtsX & Cj1472 & gi|121612126 & $-0.55 \pm 0.7$ & -1.20 (single value) \\
\hline Transformation system protein CtsP & Cj1473c & gi|121613067 & $-0.65 \pm 0.07$ & $-0.13 \pm 0.31$ \\
\hline Pyruvate-flavodoxin oxidoreductase & Cj1476c & gi|315124909 & $-0.87 \pm 0.38$ & $0.63 \pm 0.42$ \\
\hline Formate dehydrogenase, iron-sulfur subunit & Cj1510c & gi|157415732 & $-0.73 \pm 0.71$ & $-0.73 \pm 0.45$ \\
\hline Dephospho-CoA kinase & Cj1530 & gi|218563123 & $0.73 \pm 0.68$ & $0.57 \pm 0.74$ \\
\hline Multidrug transporter membrane component/ATP-binding component & Cj1587c & gi|121613099 & $1.40 \pm 0.53$ & $1.00 \pm 0.44$ \\
\hline Two-component regulator (DNA binding response regulator), putative & Cj1608 & gi|218563197 & $-0.07 \pm 0.31$ & $-2.50 \pm 1.65$ \\
\hline Citrate synthase & Cj1682C & gi|157415898 & $-0.80 \pm 0.36$ & $-0.73 \pm 0.21$ \\
\hline $50 S$ ribosomal protein $L 2$ & Cj1704c & gi|121612340 & $-0.47 \pm 0.85$ & $-0.80 \pm 0.46$ \\
\hline 2-isopropylmalate synthase & Cj1719c & gi|121612265 & $0.83 \pm 0.68$ & $0.67 \pm 0.21$ \\
\hline Hypothetical protein CJE0598 CJIE2 prophage & CJE0598 & gi|57238304 & $1.10 \pm 0.28$ & $0.77 \pm 0.4$ \\
\hline Flagellin & CJE1526 & gi|57238729 & $-0.87 \pm 0.25$ & $-0.80 \pm 0.44$ \\
\hline
\end{tabular}

(blood) in the medium, 24 were associated with iron acquisition. Proteins associated with oxidative stress defence pathways involving catalase production, the antioxidant AhpC/Tsa family protein, thioredoxin-like protein, and thioredoxin reductase, which are known to be associated with the iron acquisition pathways, were also detected (Table 6). Of the proteins that were differentially expressed in the presence or absence of blood, 8 proteins were associated with chemotaxis, molybdate transport, and methionine biosynthesis, 11 were hypothetical proteins, 3 were transporters, and 46 proteins were associated with varied or unknown functions. Expression of Per, the regulator of the oxidative stress response, was not affected by the presence or absence of blood in the medium (Additional file 4).

\section{Discussion}

Initial experiments describing the isolates characterized in this study $[3,4]$ were performed before our laboratory had the capability of doing whole genome sequencing. Because attempts to create isogenic mutants for the CJIE1 prophage have so far been unsuccessful, the isolates chosen were therefore closely matched epidemiologically, by molecular typing results, and by initial microarray analysis (data not shown). We have recently obtained whole genome sequence data for the closed and finished genome (unpublished data). The gene content is the same for all four isolates. Of the 16 single nucleotide polymorphisms (SNPs) found outside homopolymeric tracts among in the four isolates only one was present in isolate 00-2426 and not in the other three isolates (unpublished data). This SNP results in the introduction of a stop codon that truncates the serine/threonine transporter (SstT) protein after 218 amino acids in isolate 00-2426 (unpublished data); the other three isolates should express the full-length protein. While little is known about the C. jejuni SstT protein, SstT in E. coli has been characterized in cloning, expression, and reconstitution experiments as a serine transporter [21] and, so far, no further activity has been associated with this protein. We detected expression of SstT (gi|121613737) only in Experiment 3 (Additional file 4), though it was detected in both isolates 00-2425 and 002426 and was up-regulated in the presence of bile salts. In the case of isolate 00-2426 it may have been the truncated version of the protein that was detected. Alternately, the colony that was subjected to whole genome sequencing may have carried a mutation within the gene encoding this protein. Serine utilization is an important carbon source that is also critical for host colonization [22]. Proteins 
SdaC (Cj1624c) and SdaA (1625c) have been associated with serine uptake, and SdaC appears to be sufficient to transport serine into the bacterial cell [22]. All four isolates used in this study were found to carry genes capable of expressing SdaC and SdaA. Expression of SdaA (gil 218563213) was detected in all four isolates, while $\mathrm{SdaC}$ was not detected in any of the four, suggesting it may have been produced in quantities too low to be recovered by our proteomics methodology. It seems doubtful that a truncation of SstT, if actually present, would result in the changes in protein expression seen in our studies, and is more likely that the differences in the presence/absence of CJIE1 were responsible.

Comparative proteomics with iTRAQ labelling was useful for demonstrating patterns of protein regulation in response to the presence of the CJIE1 prophage, to iron levels in the media, and to the presence of two different bile salt preparations in the media. Direct evidence for an effect of the CJIE1 prophage on expression of a small number of $C$. jejuni proteins was first obtained after growth of the organisms on medium containing blood, a finding confirmed in subsequent experiments using different growth conditions ( $\mathrm{MH}$ and $\mathrm{MH}+\mathrm{SD})$. Effects on protein expression associated with the presence or absence of the CJIE1 prophage were therefore not due simply to growth on rich medium, but could be generalized to nutrient-limited media and medium containing $0.1 \%$ deoxycholate utilized previously to demonstrate induction of genes associated with C. jejuni virulence [15]. These results supported previous work indicating that the three CJIE1-carrying isolates exhibited greater adherence and invasion than the isolate without CJIE1 [3].

Additional evidence for regulation of protein expression associated with the presence or absence of CJIE1 was obtained by comparing the degree to which proteins were regulated after growth on $\mathrm{MH}$ as the reference condition, and $\mathrm{MH}+\mathrm{SD}$ or $\mathrm{MH}+\mathrm{OX}$ as the conditions used for comparison. Because the experimental design required these data to be obtained in two completely separate experiments involving either $C$. jejuni $00-2425$ $\left(\mathrm{CJIE} 1^{+}\right)$or C. jejuni 00-2426 (CJIE1 $\left.1^{-}\right)$, it was not possible to quantify absolute expression levels, only the degree of change from the reference condition.

Changes in homopolymeric tract length could only be unambiguously associated with differences in quantitative protein detection/expression for two loci, Cj0685 (CipA) and for hypothetical protein Cj1305c/CJE1505. However, the length of homopolymeric tracts has been shown to change and are likely best expressed as the ratio of organisms in a population with homopolymeric tract length enabling full-length protein expression [23]. The data do suggest the homopolymeric tracts lengths determined by whole genome sequencing were determinative of the protein expression levels found in the proteomics experiments, further suggesting that the presence or absence of the CJIE1 prophage may somehow influence the homopolymeric tract length associated with some genes. This hypothesis requires further experimentation for verification.

\section{Proteins associated with changes in expression modified by CJIE1}

The presence of CJIE1 affected the expression of 27 proteins when four isolates were grown on $\mathrm{MH}+$ blood, 19 of which were not encoded by the CJIE1 prophage (Table 1). Growth of two isolates (+/-CJIE1) on MH and $\mathrm{MH}+\mathrm{SD}$ resulted in differential expression of 27 proteins, of which 11 were also observed during growth on $\mathrm{MH}+$ blood. Only two prophage proteins were expressed on $\mathrm{MH}+/-\mathrm{SD}$, suggesting that the expression of phage structural proteins may be more favored on rich medium. It is also possible that the proteins showing differential expression on only one or the other medium, 10 of which were unique to $\mathrm{MH}+$ blood and 16 of which were unique to $\mathrm{MH}$ and $\mathrm{MH}+\mathrm{SD}$, exhibited this characteristic because of regulatory pathways specific for each growth medium. This should be a good subject for further directed studies.

The proteins regulated by CJIE1 when isolates were grown on $\mathrm{MH}+$ blood did not appear to be a random subset of the total proteins detected, either in terms of function or chromosomal location. Two of the up-regulated proteins and three of the down-regulated proteins (total $=$ $5 / 21$ or $24 \%$; Table 2) were in some way associated with O-linked glycosylation (Cj1305c, Cj1310c), capsule biosynthesis (Cj1426c), or other carbohydrate synthesis (Cj0288c, Cj0685c). Cj1426 was previously identified as one of the genes regulated by CosR [24]. Though the colocalization of genes encoding Cj1098-Cj1101 was striking, the differences in protein function of the gene products would suggest that these genes are not part of an operon. Protein expression in the presence of bile salts, compared with growth on $\mathrm{MH}+$ blood, was also different for expression of CJ1098 and Cj1101 compared with CJ1099, indicating that protein expression was not co-regulated. No obvious genomic elements that could affect transcription were noted in the region upstream of $\mathrm{Cj} 1098$ in the reannotation of the NCTC 11168 genome (NC_002163). Further work is required to verify the protein expression observations seen here and to elucidate the mechanisms by which they occur.

Each of the nine proteins exhibiting differences of expression associated with the presence or absence of the prophage on all three media appeared to have important biological functions in C. jejuni. The invasion phenotype protein (CipA) was expressed in greater amounts when CJIE1 was present, and was further up-regulated approximately two-fold by the presence of bile salts. CipA 
(Cj0685c) has been annotated as a putative sugar transferase with homology to proteins within the capsule synthesis locus [25]. Transposon mutagenesis of the gene encoding this protein reduced invasion of INT-407 and Caco- 2 cells to about $2 \%$ of wild type levels though there was minimal change in motility [26]. Major protein sequence differences in CipA were associated with loss of the capacity of the strain to invade Caco-2 cells [27]. The increased expression of this protein in isolates carrying the CJIE1 prophage might therefore be at least partly responsible for the increased invasion of INT-407 cells found in earlier work [3].

Cj1429 was also highly up-regulated on $\mathrm{MH}+$ blood in the CJIE $1^{+}$isolate (Table 1 ). This protein was also induced quite strongly by $0.1 \%$ sodium deoxycholate or $2.5 \%$ Oxgall, though the effect was not as pronounced in isolate 00-2425 carrying CJIE1. Cj1429 expression therefore appears to be part of the general bile stress response. It is annotated as a hypothetical protein, and BLAST searches provide no further clues as to its function. The gene encoding $\mathrm{Cj} 1429$ is variably present in the capsular polysaccharide biosynthesis locus [28]; it therefore constitutes a strain-specific protein that may or may not be associated with virulence. It is possible that, along with CipA, this protein may modify the sugar composition of the capsule to increase adherence and invasion of $C$. jejuni isolates. Capsular polysaccharide is associated with reduced surface hydrophobicity, increased serum resistance, increased invasion in cell culture, and increased virulence in a ferret model [29]; expression or overexpression of Cj1429 might alter these properties. Resequencing of C. jejuni NCTC11168 after serial passage in mice detected changes at several loci associated with homopolymeric tracts. The gene encoding Cj1429 was one of the loci showing significant enrichment after passage for variants in which the gene was in-frame and therefore expressed [23]. This further implicates Cj1429 as a key virulence factor.

A methyltransferase homologous to $\mathrm{Cj} 1426$ in C. jejuni NCTC11168 was also part of the capsule locus and was differentially expressed in the presence and absence of the CJIE1 prophage. This methyltransferase is responsible for adding a 6-O-Me residue onto the heptose of the capsular polysaccharide repeat unit [30].

Acetate kinase and phosphate acetyltransferase are key enzymes responsible for production of acetyl CoA, a key molecule in metabolism. Acetate kinase produces acetyl phosphate, which in E. coli is a global regulator affecting capsule biosynthesis, biofilm development, pathogenicity, flagellar biosynthesis, pilus assembly, nitrogen assimilation, and osmoregulation [31]. It was annotated as being capable of acetylating $\mathrm{CheY}$, thereby increasing signal strength during flagellar rotation (see accession number NC_002163). Acetate kinase and phosphate acetyltransferase were the second and third most highly expressed CJIE1-regulated proteins on $\mathrm{MH}+$ blood, respectively. Compared with the reference condition (growth on $\mathrm{MH}$ ), growth of isolates on $\mathrm{MH}+\mathrm{SD}$ resulted in down-regulation of acetate kinase to approximately the same extent in isolates $+/-$ CJIE1 (Table 5); this effect was much smaller on $\mathrm{MH}+\mathrm{OX}$. Despite the fact that both sodium deoxycholate and Oxgall are bile salts, it would appear the differences in composition were sufficient to elicit a slightly different regulatory response. Furthermore, the presence or absence of the CJIE1 prophage did not appear to have much effect on the decrease in expression over the reference condition (growth on $\mathrm{MH}$ ). Phosphate acetyltransferase was expressed approximately 5-fold higher in isolate 00-2425 compared to isolate 00-2426 when both isolates were grown on $\mathrm{MH}+$ blood, $\mathrm{MH}$, and $\mathrm{MH}+\mathrm{SD}$. In this case, however, the expression of the protein was increased $2-4$ fold only in the absence of CJIE1 when grown on bile salts (Table 5) compared with growth on $\mathrm{MH}$. The presence of CJIE1 appeared to abrogate the response of phosphate acetyltransferase expression to bile salts. Though associated with a common biochemical pathway, acetate kinase and phosphate acetyltransferase appear to be regulated quite differently. While little is known about the roles of these proteins in C. jejuni, they may be key regulators of a number of cellular responses, and are possible candidates for regulation of the general bile response described below. Though the genes encoding these two proteins are contiguous in the $C$. jejuni chromosome, the regulation of protein expression appeared to be quite different under the different conditions used.

Phosphate acetyltransferase and FliS have both been implicated in biofilm production due to the observation that mutants in the genes encoding each of these proteins eliminated floc formation and pellicle formation [32]. However, neither of these proteins was more highly expressed in $C$. jejuni isolates from biofilms or planktonic cells [33]. The differences in FliS expression in these studies were not significant, and it is not clear that phosphate acetyltransferase was co-regulated with this protein.

The aspartate carbamoyltransferase catalytic subunit (PyrB) was expressed at higher levels in strain 00-2425. This subunit is part of a multimeric enzyme complex that catalyzes the first step in the pyrimidine biosynthesis pathway, and controls the rate of pyrimidine biosynthesis by feedback inhibition [34,35]. Changing the expression of only the catalytic PyrB peptide could change the stoichiometry of the catalytic and regulatory sites, but it is not clear what the biological effect on the bacterial cell might be.

Recently, oligoendopeptidase F (PepF) has been characterized as a signal peptidase required for protein secretion [36]. It has been associated with changes in peptidoglycan structure when bacteria were grown in rich medium, and plays a role in pyruvate metabolism, 
including acetate production. It is possible, but speculative, that increases in expression of PepF could result in concomitant changes in protein secretion, and that this may also require the activity of acetate kinase and phosphate acetyltransferase to restore acetate homeostasis.

The ATP-dependent DNA-helicase UvrD functions to carry out DNA excision repair in stalled, regressed replication forks [37]. When this protein is overexpressed, the frequencies of recombination subsequent to conjugation or transformation are reduced, while sensitivity to ultraviolet light is increased [38], likely due to the fact that in E. coli UvrD displaces RecA from DNA [39] and mutations in $u v r D$ induce the SOS response [40]. Among other things, we speculate that these properties could suggest that overexpression of UvrD might also suppress the induction of prophages.

\section{Expression of prophage proteins, effects of CJIE1 prophage on expression, and induction of prophages by growth on bile salts}

Expression of a limited number of prophage proteins was detected in this study. As expected, proteins encoded by CJIE1 genes were detected only in isolate 00-2425, while isolate 00-2426 did not express these proteins (Table 2); these observations provide support for the validity of results and the experimental design. When grown on $\mathrm{MH}+$ blood, both the CJIE1 and CJIE4 prophages were expressed at low levels, as shown by detection of a relatively few prophage structural proteins. Only two CJIE1 prophage proteins were expressed on $\mathrm{MH}$ (Table 2), and one was a cargo gene. Presumably these two proteins were the ones most highly expressed from the prophages. Growth on either $\mathrm{MH}+\mathrm{SD}$ or $\mathrm{MH}+\mathrm{OX}$ resulted in unchanged levels of the CJIE1 repressor protein CJE0215, but increased expression of a second repressor protein, the signal peptidase I adjacent to $p a n B$ within the 00 2425 genome (Additional file 2: Table S2). An additional prophage structural protein, bacteriophage transposition protein B (CJE0269), was also detected in this experiment and was more highly expressed on media containing bile salts, consistent with induction of the prophage by bile salts. Malik-Kale and colleagues [15] also detected transcriptional up-regulation of several CJIE1 proteins in clinical C. jejuni isolate F38011 upon growth in $0.1 \%$ sodium deoxycholate. These included the phage structural protein for tail fiber $\mathrm{H}$ (CJE0230), a muramoyl-pentapeptide carboxypeptidase (CJE0241), two hypothetical proteins (CJE0230 and CJE0243) and DNA adenine methylase (CJE0220) (see [4] for updated annotation). While different loci were detected than in our current work, these results were also consistent with induction of CJIE1 by bile salts.

ORF11, a unique protein encoded by a cargo gene in a subset of $C$. jejuni isolates [3,4], and the extracellular DNase associated with loss of natural transformation
(CJE0256) were the only other CJIE1 proteins with detectable expression in this series of proteomics experiments. The DNase was downregulated by growth in both bile salt preparations. ORF 11 was not affected by changes in iron content of the medium but was induced in the presence of bile salts. The levels of induction of ORF11 were roughly similar to those of DNA transposition protein $\mathrm{B}$, so that it is not clear whether ORF11 protein expression was specifically induced by bile salts or whether the increased expression was caused by induction of the prophage with a resulting increase in copy number of the gene. The fact that this protein was one of only a few CJIE1 proteins that could be detected in all proteomics experiments suggests it may be responsible for the biological effects of the prophage [3].

There was clear induction of CJIE4 prophage genes for at least some structural and functional proteins upon growth on both $\mathrm{MH}+\mathrm{SD}$ and $\mathrm{MH}+\mathrm{OX}$ as demonstrated by the down-regulation of the phage repressor, CJE1429, and upregulation of the recombinase (CJE1418) and capsid (CJE1458) proteins (Additional file 2: Table S2). Because of the absence of demonstrable quantities of other prophage proteins, including tail proteins, it is not clear that infectious phage particles were produced. The second repressor, Cj1440, exhibited slightly increased expression only in the presence of $2.5 \%$ Oxgall in isolate CJIE1 ${ }^{-} 00$ 2426. CJIE4 capsid protein expression was lower the presence of CJIE1 than in its absence, suggesting that the presence of CJIE1 may decrease CJIE4 induction. The expression of two genes encoding the CJIE4 toxin-antitoxin protein (CJE1470) and phage terminase, small subunit protein (CJE1472) (see [41]) was also found to be up-regulated when $C$. jejuni isolate F38011 was grown on $0.1 \%$ sodium deoxycholate [15], further supporting the hypothesis that this prophage is induced by growth of the bacterium on $0.1 \%$ sodium deoxycholate.

Other CJIE4 proteins with altered expression in bile salts included the extracellular endonuclease and three hypothetical proteins (Additional file 2: Table S2). Two of these (CJE1439 and CJE1441) were within a region of variability an indel - within the CJIE4 genome (manuscript in preparation). CJE1466 was consistently expressed in all proteomics experiments, even in the absence of evidence for prophage induction, suggesting it may also be the product of a cargo gene. The DNA/RNA non-specific endonuclease (CJE1441) from CJIE4 was the only protein from this prophage with decreased expression in the presence of bile salts, exhibiting a 4-fold decrease in the presence of $0.1 \%$ sodium deoxycholate and a 7 - 7.5-fold decrease in the presence of 2.5\% Oxgall, (Additional file 2: Table S2). This endonuclease, like the CJIE1 DNase, is a non-essential protein affecting DNA-uptake and natural transformation [2]. The expression of both proteins may not be highly adaptive under conditions of bile stress. 


\section{Growth of $C$. jejuni on medium containing $0.1 \%$ sodium deoxycholate or $2.5 \%$ Oxgall provides evidence of an} adaptive bile response involving a majority of the proteome Malik-Kale et al. [15] previously suggested that the presence of $0.1 \%$ sodium deoxycholate was associated with the induction of virulence genes and a general bile stress response. Fox et al. [16] also demonstrated a response to $2.5 \%$ ox-bile involving about 48 proteins. The results presented here support the existence of a more general stress response involving a large proportion of $C$. jejuni proteins. Down-regulation in the presence of $0.1 \%$ deoxycholate was observed for most or all proteins associated with energy production and conversion, amino acid transport and metabolism, nucleotide transport and metabolism, carbohydrate transport and metabolism, coenzyme transport and metabolism, lipid transport and metabolism, transcription, post-translational modification, protein turnover, chaperones, inorganic ion transport and metabolism, and secondary metabolites biosynthesis, transport, and catabolism. Most proteins associated with cell motility were upregulated in the presence of $0.1 \%$ sodium deoxycholate, as were many within COGs associated with cell wall/membrane/ envelope biogenesis and replication, recombination, and repair. $\mathrm{CmeA}, \mathrm{CmeB}$, and $\mathrm{CmeC}$ expression was found to be increased in both this work and by Malik-Kale et al. [15]. In addition, the expression of proteins associated with the presence and induction of CJIE1 and CJIE2 was increased in both this work and that described earlier [15].

There were some consistent patterns of protein regulation known to be associated with virulence, further supporting the conclusions of Malik-Kale et al. [15]. Proteins involved in capsule synthesis and transport were upregulated in the presence of bile salts, as was the flippase involved in $\mathrm{N}$-linked glycosylation and flagellar structural genes and biosynthesis regulation. These proteins included FlhA and FlhF. FlhA plays an important role in flagella formation, motility and invasion by regulating the expression of $\sigma^{28}$ - and $\sigma^{54}$-regulated genes [7], and could other key genes as well. It is also part of the flagellar type three secretion system and the flagellar MS ring [42].

The strong and consistent down-regulation of $\mathrm{CiaB}$ in the presence of both bile salts was surprising. MalikKale et al. [15] conducted a series of transcriptomic experiments that strongly indicated expression of the $c i a B$ gene was up-regulated in the presence of $0.1 \%$ sodium deoxycholate in Mueller-Hinton agar, precisely the same conditions used in the current study. Such expression differences between transcriptomic and proteomic experiments may be attributed to post-transcriptional regulation [9]. Malik-Kale et al. [15] also found that CiaB was present in the supernatants of $C$. jejuni prepared from $\mathrm{MH}+\mathrm{SD}$ plates, suggesting that our observation of less cellular $\mathrm{CiaB}$ in isolated bacteria could have resulted from export of the protein out of the bacterial cell.

\section{Iron regulated proteins}

All iron acquisition proteins and all oxidative stress proteins showing differences in expression on $\mathrm{MH}$ medium compared with $\mathrm{MH}+$ blood have been previously described and the roles defined [43-45]. Every protein associated with the putative siderophore-uptake system (Cj1658 - Cj1663 showed higher expression on $\mathrm{MH}$ medium than on $\mathrm{MH}+$ blood, and all 5 transferrins (Cj173-175, 177, and 178) were up-regulated under conditions with decreased iron, as has previously been shown [44]. Cj177 and Cj178 were two of the three iron-regulated proteins showing the highest levels of up-regulation under lower iron concentrations. Of the five proteins associated with the ferric enterochelin-uptake system (Cj0755, Cj1352-1355), three were more highly expressed at lower iron concentrations. These were the ferric receptor CfrA (Cj0755), the enterochelin uptake ATPbinding protein CeuD (Cj1354), and the $\mathrm{ABC}$ transporter CeuE (Cj1355) [45]. The two proteins that form the inner membrane permease, CeuB (Cj1352) and CeuC (Cj1353) did not exhibit changes in expression levels when isolates were grown on $\mathrm{MH}+$ blood compared with $\mathrm{MH}$ agar. Together these observations suggest that the number of permease molecules may not be the limiting factor for uptake of iron through the ferric enterochelin-uptake system.

Increased protein expression associated with growth in lower iron concentrations was observed for all 5 proteins associated with the hemin-uptake system, which are all part of an operon, chuABCD (Cj1614-17) [44,45].

Additional known iron uptake proteins that did not demonstrate obvious regulation in the current study included a putative lipoprotein (Cj0176c), FeoA, FeoB, and a number of the proteins involved with iron-associated energy transduction systems [45]. Despite its close genetic linkage to the genes encoding the transferrins, the gene encoding Cj0176c is not a part of the two operons that include the genes encoding the transferrins [46]; this is consistent with the differences in expression seen here. Palyada and colleagues [47] previously observed that no significant differences in expression of FeoA and FeoB were seen upon changing the level of ferrous iron in the medium, which was taken as verification that FeoB is not required for ferrous iron uptake in $C$. jejuni [48]. It was of interest that only three (ExbB1, Cj0179; ExbD2, Cj1629; TonB, Cj0753) of the nine proteins known to be associated with energy transduction systems showed changes in expression resulting from changes in iron content in the growth medium. It is possible that TonB may function with any of the ExbBD uptake systems [45]. Despite being encoded by genetically unlinked loci, perhaps ExbB1 and ExbD2 associate to form a functional energy transduction system as well. Importantly, Palyada and colleagues [47] found that proteins associated with all three Exb energy transduction systems showed changes in protein expression associated 
with differences in iron availability in transcriptomic experiments. The reasons for the different pattern of expression seen for these specific proteins in the current study are not clear and require further investigation.

Iron regulation and the oxidative stress response are tightly linked $[43,46]$. The oxidative stress response responds to iron released by oxidative destruction of ironsulfur centers in proteins [42] and is responsive to iron levels in the bacterium's environment. As expected catalase, the antioxidant AhpC protein, and two thioredoxins exhibited higher levels of expression at lower levels of iron in the growth medium [45,47]. MsrA (Cj0637c) was also up-regulated in conditions of lower iron concentration, but only in the C. jejuni 00-2425 isolate carrying CJIE1. Methionine sulfoxide reductases reverse the oxidative destruction of methionine residues by catalyzing the conversion of methionine sulfoxides back to methionines, utilizing thioredoxin(s) as the electron donor [45]. The presence of CJIE1 might provide an adaptive function under conditions of oxidative stress not present in isolates without the prophage. Three methionine biosynthesis proteins were upregulated in medium with lower iron concentrations (Table 6); this could be part of the response to the destruction of methionines by oxidation under conditions of oxidative stress. Homoserine serves as a precursor for both methionine and S-adenosyl methionine (SAM) biosynthesis. SAM is a major methyl donor in cell metabolism [49]; this could provide another functional rationale for upregulation of proteins involved in methionine biosynthesis.

Ferredoxin expression was decreased when isolates were grown on $\mathrm{MH}$ medium without blood (Table 6), consistent with earlier data showing that this protein is induced in the presence of iron $[47,50]$. Ferredoxin has been classified as a protein involved in electron transport [44]; it may also be involved in the oxidative stress response $[47,50]$. Additional proteins found to be regulated by iron in the current study have also been detected in earlier studies, namely ThiC [47] and Cj1587 [44].

The results of the comparative proteomics experiments presented here corresponded to what was already known about the response to iron in C. jejuni. This validates the methods and experimental design, and strongly supports the credibility of the other data collected in these experiments. Furthermore, these observations suggest that proteins that did not appear to be regulated in a statistically significant manner may still have biologically relevant changes in expression.

A number of other iron-regulated proteins were identified as such for the first time in this study. MetE (Cj1201), Cj1200 are proteins regulated by LuxS/AI-2 (autoinducer 2 ) in the presence of hydrogen peroxide (oxidative stress) [49]. Cj0425, a putative periplasmic protein identified in bioinformatics analysis as having a high probability of association with oxygen tolerance [51], was up-regulated by decreased iron only in the presence of CJIE1 and expressed at lower levels in the presence of bile salts. An ATP-dependent CLP protease ATP-binding subunit was identified as well in this study as part of the stress response; a similar protein was detected as being subject to iron regulation in the current study (Table 6), but was annotated as being similar to homologs from a number of Treponema isolates. This protein may, in fact, be part of the oxidative stress response.

\section{Conclusions}

The presence of the CJIE1 prophage appeared to selectively affect the expression of a small proportion of virulence-associated proteins of $C$. jejuni. This could be of benefit for the $C$. jejuni bacterium by facilitating adaptation to immediate environmental changes as the bacterium traverses the gut of the infected human and preadaptation to the niche in which the organism is capable of invading host cells and tissues. There was also a general bile response involving a majority of protein expressed by the organism. The presence of bile salts appears to be a signal for induction of both CJIE1 and CJIE4 prophages. Prophage induction within the gut could result in transmission of the temperate phage to new bacterial hosts or the creation of diversity within the $C$. jejuni population through movement and integration of the prophage into new chromosomal locations or the generation of large chromosomal rearrangements [52].

\section{Methods}

\section{Isolates and growth conditions}

The isolates used were chosen because they were all outbreak type 1 from the large waterborne outbreak in Walkerton, ON, Canada in 2000 [53] and the genomes were very similar in microarray, Southern blotting, and PCR experiments, except for the presence (isolates 00$2425,00-2538$, and $00-2544)$ and absence (00-2426) of the CJIE1 prophage $[3,53]$. These findings were generally confirmed by the closed and finished whole genome sequence data (data not shown). Of the 16 single nucleotide polymorphisms (SNPs) found outside homopolymeric tracts among all 4 isolates, only one was present in isolate $00-2426$ and not in the other 3 isolates (data not shown). This SNP results in the introduction of a stop codon that truncates the serine/ threonine transporter (SstT) protein after 218 amino acids (data not shown). These data will be included in a future publication. In addition, a large plasmid was detected in isolate 00-2544. Accession numbers for whole genome sequences are 00-2425, CP006729; 00-2426, CР006708; 00-2538, СР006707; 00-2544, СР006709 (genome) and CP006710 (plasmid). CJIE1 was inserted between panB (Cj0298c homolog) and a gene encoding beta-lactamase (Cj0299 homolog) in isolates 00-2425 
and 00-2538, and into the gene encoding the McrB restriction endonuclease McrB subunit (homolog of Cj0139) in isolate 00-2544 [unpublished data]. The use of three isolates carrying CJIE1 therefore provided a control for the position of the prophage in the chromosome. Three prophage-carrying isolates were originally also used as a strategy to minimize any possible effect(s) due any undetected genetic or DNA sequence changes such as SNPs, since whole genome sequence data for these isolates has only been obtained very recently. Comparisons of the three isolates carrying CJIE1 with the isolate lacking this prophage have previously shown differences in adherence and invasion [3].

C. jejuni isolates were routinely grown on Oxoid Mueller-Hinton agar (Oxoid Inc., Nepean, ON) containing 10\% sheep red blood cells $(\mathrm{MH}+$ blood) for 48 $72 \mathrm{~h}$ at $37^{\circ} \mathrm{C}$ under microaerobic atmosphere $\left(5 \% \mathrm{O}_{2}\right.$, $10 \% \mathrm{CO}_{2}, 85 \% \mathrm{~N}_{2}$ ). Further investigations were aimed at determining whether any changes in protein expression due to the presence or absence of the CJIE1 prophage could be replicated under conditions thought to induce virulence genes, as well as whether any such differences were apparent only in the presence of sodium deoxycholate or in the presence of bile salts in general. To this end isolates were also grown on Mueller-Hinton agar $(\mathrm{MH}), \mathrm{MH}$ containing $0.1 \%$ sodium deoxycholate (Sigma-Aldrich), designated $\mathrm{MH}+\mathrm{SD}$ (or SD where space is restricted), and $\mathrm{MH}$ containing 2.5\% BD Difco Oxgall (BD Biosciences, Mississauga, ON), designated $\mathrm{MH}+\mathrm{OX}$ (or OX where space is restricted). Storage was in either $20 \%$ skim milk or glycerol peptone water $(25 \% \mathrm{v} / \mathrm{v}$ glycerol, $10 \mathrm{~g} / \mathrm{L}$ neopeptone, $5 \mathrm{~g} / \mathrm{L} \mathrm{NaCl})$ at $-80^{\circ} \mathrm{C}$.

\section{Crude protein preparation from whole bacterial cells}

The proteomics methods used were based partly on those previously published by Wiśniewski et al. [54]. C. jejuni were grown microaerobically on at least three plates of each culture medium for $48 \mathrm{~h}$ at $37^{\circ} \mathrm{C}$; more plates were required for cultures on $\mathrm{MH}+\mathrm{OX}$ due to the significant growth inhibition of the Oxgall. Bacteria on plates were suspended in $1 \mathrm{ml}$ sterile Dulbecco's PBS, pH 7.0 - 7.2 (Gibco; Invitrogen) using a sterile spreader; fractions from different plates were collected into a sterile $15 \mathrm{ml}$ centrifuge tube. After centrifugation for $15 \mathrm{~min}$ at $1455 \times \mathrm{g}$ the bacterial pellets were suspended in fresh PBS, and the contents of the tube were transferred to a $1.5 \mathrm{ml}$ microfuge tube. This suspension was centrifuged at $16,000 \times \mathrm{g}$ in a microfuge and the PBS was removed. At this point the sample was either used for the next step of the protein preparation protocol or frozen for up to 2 weeks at $-20^{\circ} \mathrm{C}$.

A $250 \mu \mathrm{l}$ volume of sterile $18 \mathrm{M} \Omega$ (MilliQ) water was added to the pelleted bacteria. About $100 \mu$ of acid- washed 212 - $300 \mu \mathrm{m}$ glass beads (Sigma-Aldrich Canada Ltd., Oakville, ON) was added to each tube and the bacteria were resuspended by vortexing for $10 \mathrm{~s}$ at the highest setting. The resulting suspensions were boiled for $5 \mathrm{~min}$ in a boiling water bath. Another $250 \mu$ l of sterile MilliQ water was added and the suspensions were lysed by incubating for $5 \mathrm{~min}$ at low speed on a Genie 2 vortex mixer fitted with a 12 place Ambion Vortexer Adapter for Genie 2 Vortex Mixer attachment (Applied Biosystems Canada, Mississauga, ON); this constituted a "bead-beating" step. After centrifugation for $1 \mathrm{~min}$ at $3000 \mathrm{rpm}(664 \times \mathrm{g})$ in a microfuge the cloudy, protein-containing supernatant was collected into a sterile $15 \mathrm{ml}$ centrifuge tube. Addition of $500 \mu \mathrm{l}$ MilliQ water, vortexing, bead-beating, centrifugation, and collection of supernatant were repeated until the supernatant was clear. Protein preparations were used immediately or stored at $-80^{\circ} \mathrm{C}$ for up to two months.

The protein concentration of each preparation was estimated using a Pierce Protein Assay kit (Fisher Scientific, Whitby, ON) according to the manufacturer's protocol.

\section{Protein modification and digestion}

Crude protein suspensions containing $100 \mu \mathrm{g}$ protein were placed in $1.5 \mathrm{ml}$ microfuge tubes and dried without heating in a Savant DNA120 SpeedVac Concentrator (Fisher Scientific). Each protein preparation was suspended in $50 \mu \mathrm{l}$ of freshly made SDS solubilization buffer (4\% SDS, $50 \mathrm{mM}$ HEPES buffer $\mathrm{pH} 8.3,100 \mathrm{mM}$ DTT), heated at $95^{\circ} \mathrm{C}$ for $5 \mathrm{~min}$, and placed in a $-20^{\circ} \mathrm{C}$ freezer overnight. The following morning Nanosep $10 \mathrm{~K}$ cartridges (VWR International LLC, Mississauga, ON) were prepared by first adding $200 \mu \mathrm{l}$ water to the cartridge and centrifuging at $10,000 \times \mathrm{g}$ for $10 \mathrm{~min}$, then by adding $200 \mu \mathrm{l}$ of fresh Urea Exchange Buffer (UEB; $8 \mathrm{M}$ urea in $50 \mathrm{mM}$ HEPES, $\mathrm{pH}$ 8.3) and centrifuging at $10,000 \times \mathrm{g}$ until all liquid was removed from the cartridge.

A 7-fold volume $(350 \mu \mathrm{l})$ of UEB was added to each $50 \mu \mathrm{l}$ of protein in SDS solubilization buffer. Samples were then placed into the prepared Nanosep spin filter cartridges and centrifuged at $10,000 \times \mathrm{g}$. After removing the flow-through, samples were washed twice with UEB, each time centrifuging to remove almost all liquid in the cartridge and discarding the flow-through.

Proteins were then alkylated by adding $100 \mu \mathrm{l}$ of $50 \mathrm{mM}$ iodoacetamide (IAA Reagent, Sigma-Aldrich) in UEB and shaking for $5 \mathrm{~min}$ at RT on an MBI Thermo-Shaker (Montreal Biotech, Kirkland, PQ, Canada) covered with tin foil, followed by a further $20 \mathrm{~min}$ incubation without shaking in the dark, followed by centrifugation at $10,000 \times \mathrm{g}$ for approximately $10 \mathrm{~min}$. The spin filter was washed three times with UEB, centrifuging and discarding the flow-through as above each time to remove almost all liquid. The buffer was then exchanged by washing twice 
with $150 \mu \mathrm{l}$ of $50 \mathrm{mM}$ HEPES, $\mathrm{pH}$ 8.3, centrifuging and discarding the flow-through as above each time to remove almost all liquid.

DNA was removed by the addition of $50 \mu$ of freshly made Benzonase (Sigma-Aldrich) solution ( $20 \mathrm{U} / \mu \mathrm{l}$ Benzonase in $42 \mathrm{mM}$ HEPES, $\mathrm{pH} 8.3$ containing $2 \mathrm{mM}$ $\mathrm{MgCl}_{2}$ ) to the membrane followed by mixing at $600 \mathrm{rpm}$ for $2 \mathrm{~min}$ at RT on an MBI Thermo-Shaker and incubation for $30 \mathrm{~min}$ at RT. After this incubation, the cartridge was washed three times with $100 \mu \mathrm{l}$ of $50 \mathrm{mM}$ HEPES, $\mathrm{pH}$ 8.3, centrifuging and discarding the flowthrough as above each time to remove almost all liquid.

One vial $(100 \mu \mathrm{g})$ of trypsin (Trypsin Gold, mass spectrometry grade, Promega ) was previously dissolved in $100 \mu \mathrm{l}$ of $0.1 \%$ formic acid ( $\mathrm{vol} / \mathrm{vol})$, distributed in $5 \mu \mathrm{l}$ $(5 \mu \mathrm{g})$, and kept frozen at $-20^{\circ} \mathrm{C}$. To prepare fresh solution just before use for trypsinization of proteins, $45 \mu \mathrm{l}$ of $50 \mathrm{mM}$ HEPES, pH 8.3 was added to a $5 \mu \mathrm{l}(5 \mu \mathrm{g})$ trypsin for each sample to be trypsinized. This was added to each cartridge, mixed for $1 \mathrm{~min}$ at $600 \mathrm{rpm}$ at RT on an MBI Thermo-Shaker followed by incubation $\mathrm{ON} \min$ at $37^{\circ} \mathrm{C}$ in a humidified atmosphere. The next day peptides were recovered from the cartridge. First $50 \mu \mathrm{l}$ of $50 \mathrm{mM}$ HEPES, pH 8.3 was to the $50 \mu$ trypsin digest in the cartridge and mixed at $600 \mathrm{rpm}$ for $3 \mathrm{~min}$ at RT. The cartridge was then inverted and placed into a fresh microfuge collection tube, followed by centrifugation in the microfuge at $10,000 \times \mathrm{g}$ for $1 \mathrm{~min}$. The addition of buffer to the cartridge and subsequent centrifugation was done twice more to ensure optimal peptide yield, resulting in a final $200 \mu \mathrm{l}$ volume. The pooled peptide solution was frozen at $-20^{\circ} \mathrm{C}$ until peptides were either labelled with iTRAQ reagents or used as unlabelled peptide preparations in liquid chromatography and mass spectrometry.

\section{iTRAQ labelling}

Peptides were first dried without heating in a Savant DNA120 SpeedVac Concentrator, then suspended in $30 \mu \mathrm{l} 100 \mathrm{mM}$ HEPES, pH 8.3. $70 \mu \mathrm{l}$ 100\% ethanol was added to each iTRAQ label and the resulting solution was mixed by vortexing at high speed for $30 \mathrm{~s}$ followed by vortexing at medium speed for $30 \mathrm{~min}$ in a foam vortexer adapter. Each iTRAQ label solution was then added to a peptide mixture, vortexed $20 \mathrm{~s}$ at the highest setting, collected by centrifugation in a microfuge, and incubated ON at RT. The next day $150 \mu \mathrm{l}$ sterile MilliQ water was added to quench the labelling reaction and the mixtures were dried in the SpeedVac concentrator. These mixtures were frequently stored at $-20^{\circ} \mathrm{C}$ until the next step.

Labelled peptides were thawed, dissolved in $40 \mu \mathrm{l}$ water, vortexed for $30 \mathrm{~min}$ on medium, and centrifuged in a microfuge for $2 \mathrm{~min}$ at $16,000 \times \mathrm{g}$ to remove insoluble material. After removal of supernatant to a fresh tube, $1 \mu \mathrm{l}$ of each labelled peptide mix was added to $56 \mu$ nano LC buffer A (2\% acetonitrile, $0.1 \%$ formic acid) in a $300 \mu$ PTFE vial. These pre-scans were subject to separation by nano liquid chromatography as outlined below and the results were used to normalize the amount of each labelled peptide mixture for chromatography and mass spectrometry. Labelled peptide fractions were mixed to provide the same amount of peptide using approximately $10 \mu \mathrm{l}$ volumes of each labelled peptide.

\section{Liquid chromatography and mass spectrometry}

iTRAQ-labelled tryptic peptide samples $(100 \mu \mathrm{g})$ were fractionated by high-pH, $\mathrm{C}_{18}$-reversed phase liquid chromatography on a micro-flow Agilent 1100/1200 series system (Agilent Technologies), using a Waters XBridge $\mathrm{C}_{18}$ guard column (10 mm long, $2.1 \mathrm{~mm}$ inner diameter, $3.5 \mu \mathrm{m}$ particles) and a Waters XBridge $\mathrm{C}_{18}$ analytical column $(10 \mathrm{~cm}$ long, $2.1 \mathrm{~mm}$ inner diameter, $3.5 \mu \mathrm{m}$ particles). Mixed peptides were dried and suspended in LC buffer A (20 mM ammonium formate, $\mathrm{pH} 10)$, then resolved by a gradient of LC buffer A and buffer B (20 $\mathrm{mM}$ ammonium formate and 90\% acetonitrile, $\mathrm{pH}$ 10). The gradient started at 3\% B from 0-10 min, 811\% B from 10-17 min; 11-60\% B from 17-75 min; $95 \%$ B from $75-80 \mathrm{~min}$; and 3\% B from $80-170 \mathrm{~min}$ at a constant flow rate of $150 \mu \mathrm{l} / \mathrm{min}$. Fractions were collected across the peptides elution profile (10-75 min). Fractions were dried and resuspended in $40 \mu \mathrm{l}$ of nano LC buffer A.

Each fraction was separately analysed using a nanoflow Easy nLC II (Thermo Fisher Scientific) connected in-line to an LTQ Orbitrap Velos mass spectrometer (Thermo Fisher Scientific) with a nanoelectrospray ion source (Thermo Fisher Scientific). The peptide fractions $(5 \mu \mathrm{l})$ were loaded onto a $\mathrm{C}_{18}$-reversed phase trap column ( $2 \mathrm{~cm}$ long, $100 \mu \mathrm{m}$ inner diameter, $5 \mu \mathrm{m}$ particles) with $100 \%$ buffer A ( $2 \%$ acetonitrile, $0.1 \%$ formic acid) at $4 \mu \mathrm{l} / \mathrm{min}$ for a total volume of $30 \mu \mathrm{l}$, and then separated on a $\mathrm{C}_{18}$-reversed phase column $(10 \mathrm{~cm}$ long, $75 \mu \mathrm{m}$ inner diameter, $3 \mu \mathrm{m}$ particles). Both columns were packed in-house with ReproSil-Pur $\mathrm{C}_{18}$-AQ resin (Dr. Maisch). Peptides were eluted using a linear gradient of 0-30\% buffer B (98\% acetonitrile, $0.1 \%$ formic acid) over $120 \mathrm{~min}$ at a constant flow rate of $300 \mathrm{nl} / \mathrm{min}$. Total LC/ MS/MS run-time was 160 minutes, including the loading, linear gradient, column wash at $95 \%$ buffer B, and the equilibration.

Data were acquired using a data-dependent method, dynamically choosing the top 10 abundant precursor ions from each survey scan for isolation in the LTQ and fragmentation by $\mathrm{HCD}$ at $45 \%$ normalized collision energy. The survey scans were acquired in the Orbitrap over $m / z 300-1700$ with a target resolution of 60,000 at 
$m / z 400$, and the subsequent fragment ion scans were acquired in the Orbitrap over a dynamic $m / z$ range with a target resolution of 7500 at $m / z 400$. The lower threshold for selecting a precursor ion for fragmentation was 1000 counts. Dynamic exclusion was enabled using a list size of 500 features, a $\mathrm{m} / \mathrm{z}$ tolerance of $15 \mathrm{ppm}$, a repeat count of 1 , a repeat duration of $30 \mathrm{~s}$, and an exclusion duration of $15 \mathrm{~s}$, with early expiration disabled.

\section{Data processing}

All spectra were processed using Mascot Distiller v2.3.2 (Matrix Science), and database searching was done with Mascot v2.3 (Matrix Science). Searches were performed against an in-house built, non-redundant database consisting of NCBI's Genome database of bacteria [ftp://ftp.ncbi. nlm.nih.gov/genomes/Bacteria/] and prophage sequences generated in-house. The decoy database option was selected and the following parameters were used: carbamidomethylation (C) and iTRAQ ( $\mathrm{K}$ and N-terminus) as fixed modifications, oxidations $(\mathrm{M})$ as a variable modification, fragment ion mass tolerance of $0.5 \mathrm{Da}$, parent ion tolerance of $10 \mathrm{ppm}$, and trypsin enzyme with up to 1 missed cleavage. Mascot search results were imported into Scaffold Q + v3.4 (Proteome Software) and filtered using $80 \%$ confidence for peptides, $99 \%$ confidences for proteins, and at least 2 peptides per protein.

PCR and DNA sequencing for determining the presence and sequence integrity of genes encoding highly downregulated proteins in isolate 00-2426 without CJIE1

To confirm whether selected genes encoding selected proteins had changes in their promoters or coding regions PCR was done using the primers and conditions summarized in Additional file 2: Table S1 and using methods described previously [4]. The $\mathrm{MgCl}_{2}$ concentration was $2.0 \mathrm{mM}$ in all cases.

\section{Data analysis for figure}

Data from three biological replicates of each strains (2425 and 2426) grown in 4 media $(\mathrm{MH}, \mathrm{MH}+$ blood, SD and OX) was exported from Scaffold v.3.4.5. (1) and formatted in Excel. GI numbers and Log2 fold-changes were imported in DanteR v.0.1.1. (available from [http:// omics.pnl.gov/software/DanteR.php]) for cluster analysis. For each strain, two factors (Replicate and Media) were assigned to the data table. Hierarchical clustering was performed on columns and rows using Euclidean distance and the complete linkage agglomeration method.

\section{Availability of supporting data}

Some of the supporting data have been included as Additional files 1, 3, and 4. These files represent the Excel Samples Report created by the Scaffold software after removal of entries for which there was no $\log _{2}$ change values

and after calculating means for each group of data. Accession numbers for whole genome sequences are 00-2425, CP006729; 00-2426, CР006708; 00-2538, CP006707; 002544, CP006709 (genome) and CP006710 (plasmid).

The mass spectrometry proteomics data have been deposited to the ProteomeXchange Consortium (http:// www.proteomexchange.org) via the PRIDE partner repository [55] with the dataset identifiers PXD000798, PXD000799, PXD000800, and PXD000801.

Data for experiment 1 have been deposited under the ProteomeXchange title "Effects of Campylobacter jejuni CJIE1 prophage on protein expression experiment 1" with the dataset identifier PXD000798. The iTRAQ labels for this experiment (all three replicates) were for $C$. jejuni isolate: 00-2425, 114; 00-2426, 115; 00-2538, 116, 00-2544, 117.

Data for experiment 2 have been deposited under the ProteomeXchange title "Effects of Campylobacter jejuni CJIE1 prophage on protein expression experiment 2" with the dataset identifier PXD000799. The iTRAQ labels for this experiment were different for each replicate experiment as in the following description. Replicate Y1: 00-2425 grown on $\mathrm{MH}$ agar, 114; 00-2425 grown on $\mathrm{MH}+\mathrm{SD}, 115 ; 00-2426$ grown on $\mathrm{MH}$ agar, 116; 00-2426 grown on $\mathrm{MH}+\mathrm{SD}, 117$. Replicate $\mathrm{Y2}$ : 00-2425 grown on $\mathrm{MH}$ agar, 115; 00-2425 grown on $\mathrm{MH}+\mathrm{SD}, 116 ; 00-2426$ grown on $\mathrm{MH}$ agar, 117; 00-2426 grown on $\mathrm{MH}+\mathrm{SD}$, 114. Replicate Y3: 00-2425 grown on $\mathrm{MH}$ agar, 116; 002425 grown on $\mathrm{MH}+\mathrm{SD}, 117 ; 00-2426$ grown on $\mathrm{MH}$ agar, 114; 00-2426 grown on $\mathrm{MH}+\mathrm{SD}, 115$.

Data for experiment 3 have been deposited under the ProteomeXchange title "Effects of Campylobacter jejuni CJIE1 prophage on protein expression experiment 3" with the dataset identifier PXD000800. The iTRAQ labels for this experiment (all three replicates) were for $C$. jejuni isolate 00-2425 grown on: $\mathrm{MH}+$ blood, 114; $\mathrm{MH}$ agar, 115; $\mathrm{MH}+\mathrm{SD}, 116 ; \mathrm{MH}+\mathrm{OX}, 117$.

Data for experiment 4 have been deposited under the ProteomeXchange title "Effects of Campylobacter jejuni CJIE1 prophage on protein expression experiment 4" with the dataset identifier PXD000801. The iTRAQ labels for this experiment (all three replicates) were for $C$. jejuni isolate 00-2426 grown on: $\mathrm{MH}+$ blood, $114 ; \mathrm{MH}$ agar, 115; MH + SD, 116; MH + OX, 117.

\section{Additional files}

Additional file 1: Experiment 1 data from Scaffold.
Additional file 2: Supplementary tables.
Additional file 3: Experiment 2 data from Scaffold.
Additional file 4: Experiment 3 and 4 data from Scaffold, combined.

Competing interests

The authors declare that they have no competing interests. 


\section{Authors' contributions}

Conceived and designed the work: CGC. Performed laboratory experiments: CGC, PC, SJM, KC, DML, KN. Performed Mascot and Scaffold analysis: GRW. Bioinformatics analysis and annotation of whole genome sequence: MW, CGC. Performed statistical analysis and figure: CGC, PS. Performed all other data analysis: CGC. Wrote the manuscript: CGC. Provided assistance with funding, acquisition of additional supplies and a Co-op student (KN), and valuable advice for the written manuscript: MWG. All authors have read and approved the final manuscript

\section{Acknowledgements}

Thanks to the Genomics and the Bionformatics Core Facilities at the NML for performing whole genome sequencing and initial steps in sequence generation. Philip Mabon contributed to the whole genome sequence analysis and submission of genome sequence data of the four C. jejuni isolates used in this work. Cai Guan prepared DNA for whole genome sequence analysis. We greatly appreciate the efforts of the PRIDE team in helping us to painlessly deposit the protein ITRAQ data to

ProteomeXchange. Thanks to Dr. W. Cuff for an exhaustive and detailed analysis and assessment of the statistics associated with proteomic package Scaffold. The funding source was Government of Canada A-base funds.

\section{Author details}

${ }^{1}$ Enterics Research Section, Bacteriology and Enterics Program, National Microbiology Laboratory, Public Health Agency of Canada, 1015 Arlington St, Winnipeg, Manitoba R3E 3R2, Canada. ${ }^{2}$ Mass Spectrometry and Proteomics Core Facility, National Microbiology Laboratory, Public Health Agency of Canada, 1015 Arlington St, Winnipeg, Manitoba R3E 3R2, Canada. ${ }^{3}$ Department of Medical Microbiology, University of Manitoba, Room 543 745 Bannatyne Avenue, Winnipeg, Manitoba R3E 3J9, Canada. ${ }^{4}$ Special Pathogens Program, National Microbiology Laboratory, Public Health Agency of Canada, 1015 Arlington St, Winnipeg, Manitoba R3E 3R2, Canada. ${ }^{5}$ Current address: Faculty of Pharmacy, Apotex Centre, University of Manitoba, Winnipeg, Manitoba R3E 0T5, Canada.

Received: 28 May 2013 Accepted: 10 March 2014

Published: 19 March 2014

\section{References}

1. Gaasbeek EJ, Wagenaar JA, Guilhabert MR, Wösten MMSM, van Putten JPM, van der Graaf-van Bloois L, Parker CT, van der Wal FJ: A DNase encoded by the integrated element CJIE1 inhibits natural transformation of Campylobacter jejuni. J Bacteriol 2009, 191:2296-2306.

2. Gaasbeek E, Wagenaar JA, Guilhabert MR, van Putten JPM, Parker $C T$, van der Wal FJ: Nucleases encoded by the integrated elements CJE2 and CJIE4 inhibit natural transformation of Campylobacter jejuni. J Bacteriol 2010, 192:936-941.

3. Clark CG, Grant CCR, Pollari F, Marshall B, Moses J, Tracz DM, Gilmour MW: Effects of the Campylobacter jejuni CJIE1 prophage homologs on adherence and invasion in culture, patient symptoms, and source of infection. BMC Microbio/ 2012, 12:269

4. Clark CG: Sequencing of CIE1 prophages from Campylobacter jejuni reveals the presence of inserted and (or) deleted genes. Can J Microbio/ 2011, 57:795-809.

5. Andersen MT, Brøndsted L, Pearson BM, Mulholland F, Parker M, Pin C, Wells $\mathrm{JM}$, Ingmer H: Diverse roles for HspR in Campylobacter jejuni revealed by the proteome, transcriptome, and phenotypic characterization of an hspR mutant. Microbiology 2005, 151:905-915.

6. Bièche $C$, de Lamballerie $M$, Chevret $D$, Federighi $M$, Tresse O: Dynamic proteome changes in Campylobacter jejuni 81-176 after high pressure shock and subsequent recovery. J Proteomics 2012, 75:1144-1156.

7. Carrillo CE, Taboada E, Nash JHE, Lanthier P, Kelly J, Lau PC, Verhulp R, Mykytczuk O, Sy J, Findlay WA, Amoako K, Gomis S, Willson P, Austin JW, Potter A, Babiuk L, Allan B, Szymanski CM: Genome-wide expression analysis of Campylobacter jejuni NCTC11168 reveals coordinate regulation of motility and virulence by flhA. J Biol Chem 2004, 279:20327-20338.

8. Liu X, Gao B, Novik V, Galán JE: Quantitative proteomics of intracellular Campylobacter jejuni reveals metabolic reprogramming. PLOS Pathog 2012, 8:e1002562.

9. Sampathkumar B, Napper S, Carrillo CD, Willson P, Taboada E, Nash JHE, Potter AA, Babiuk LE, Allan BJ: Transcriptional and translational expression patterns associated with immobilized growth of Campylobacter jejuni. Microbiology 2006, 152:567-577
10. Seal BS, Hiett KL, Kuntz RL, Woolsey R, Schegg KM, Ard M, Stinzi A: Proteomic analysis of a robust versus a poor chicken gastrointestinal colonizing isolate of Campylobacter jejuni. J Proteome Res 2007, 6:4582-4591.

11. Malmström L, Malmström J, Aebersold R: Quantitative proteomics of microbes: principles and applications to virulence. Proteomics 2011, 11:2947-2956.

12. Pieper R, Zhang Q, Clark DJ, Huang S-T, Suh M-J, Braisted JC, Payne SH, Fleischmann RD, Peterson SN, Tzipori S: Characterizing the Escherichia coli 0157:H7 proteome including protein associations with higher order assemblies. PLoS One 2011, 6:e26554.

13. Unwin RD, Griffiths JR, Whetton AD: Simultaneous analysis of relative protein expression levels across multiple samples using iTRAQ isobarictags with 2D nano LC-MS/MS. Nat Protoc 2010, 5:1574-1582.

14. Soares NC, Cabral MP, Gayoso C, Mallo S, Rodriguez-Velo P, Fernández Moreira E, Bou G: Associating growth-phase-related changes in the proteome of Acinetobacter baumanii with increased resistance to oxidative stress. J Proteome Res 2010, 9:1951-1964.

15. Malik-Kale P, Parker $C$, Konkel ME: Culture of Campylobacter jejuni with sodium deoxycholate induces virulence gene expression. J Bacteriol 2008, 190:2286-2297.

16. Fox EM, Raftery M, Goodchild A, Mendz GL: Campylobacter jejuni response to ox-bile stress. FEMS Immunol Med Microbiol 2007, 49:165-172.

17. Okoli AS, Wadstrom T, Mendz GL: Bioinformatic study of bile responses in Campylobacteriales. FEMS Immunol Med Microbiol 2007, 49:101-123.

18. Barton C, Ng L-K, Tyler SD, Clark CG: Temperate bacteriophages affect pulsed-field gel electrophoresis patterns of Campylobacter jejuni. J Clin Microbiol 2007, 45:386-391.

19. Scott NE, Cordwell SJ: Campylobacter proteomics: guidelines, challenges and future perspectives. Expert Rev Proteomics 2009, 6:62-74.

20. Dasti Jl, Tareen M, Lugert R, Zautner AE, Groß U: Campylobacter jejuni: a brief overview on pathogenicity-associated factors and diseasemediating mechanisms. Int J Med Microbiol 2010, 300:205-211.

21. Kim Y-M, Ogawa W, Tamai E, Kuroda T, Mizushima T, Tsuchiya T: Purification, reconstitution, and characterization of $\mathrm{Na}^{+}$/serine symporter, $\mathrm{SstT}$, of Escherichia coli. J Biochem 2002, 132:71-76.

22. Stahl M, Butcher J, Stintzi A: Nutrient acquisition and metabolism by Campylobacter jejuni. Frontiers Cell Infect Microbiol 2012, 2:5.

23. Jerome JP, Bell JA, Plovanich-Jones AE, Barrick JE, Brown CT, Mansfield LS: Standing genetic variation in contingency loci drives the rapid adaptation of Campylobacter jejuni to a novel host. PLoS One 2011, 6:e16399.

24. Hwang S, Kim M, Ryu S, Jeon B: Regulation of oxidative stress response by CosR, an essential response regulator in Campylobacter jejuni. PLoS One 2011, 6:e22300.

25. Parkhill J, Wren B, Mungall K, Ketley JM, Churcher C, Basham D, Chillingworth T, Davies RM, Feltwell T, Holroyd S, Jagels K, Karlyshev AV, Moule S, Pallens MJ, Penn CW, Quail MA, Rajandream M-A, Rutherford KM, van Vliet AHM, Whitehead S, Barrell BG: The genome sequence of the food-borne pathogen Campylobacter jejuni reveals hypervariable sequences. Nature 2000, 403:665-668

26. Javed MA, Grant AJ, Bagnall MC, Maskell DJ, Newell DG, Manning G: Transposon mutagenesis in a hyper-invasive clinical isolate of Campylobacter jejuni reveals a number of genes with potential roles in invasion. Microbiology 2010, 156:1134-1143.

27. Poli VFS, Thorsen L, Olesen I, Wik MT, Jespersen L: Differentiation of the virulence potential of Campylobacter jejuni strains by use of gene transcription analysis and a Caco-2 assay. Int J Food Microbiol 2012, 155:60-68.

28. Karlyshev AV, Champion OL, Churcher C, Brisson J-R, Jarrell HC, Gilbert M, Brochu D, St. Michael F, Wakarchuk WW, Goodhead I, Sanders M, Stevens K, White B, Parkhill J, Wren BW, Szymanski CM: Analysis of Campylobacter jejuni capsular loci reveals multiple mechanisms for the generation of structural diversity and the ability to form complex heptoses. Mol Microbiol 2005, 55:90-103.

29. Bacon DJ, Szymanski CM, Burr DH, Silver RP, Alm RA, Guerry P: A phasevariable capsule is involved in virulence of Campylobacter jejuni 81-176. Mol Microbiol 2001, 40:769-777.

30. Sternberg MJE, Tammaddoni-Nezhad A, Lesk VI, Kay E, Hitchen PG, Cootes A, van Alphen LB, Lamoureux MP, Jarrell HC, Rawlings CI, Soo EC, Szymanski CM, Dell A, Wren BW, Muggleton SH: Gene function hypotheses for the Campylobacter jejuni glycome generated by a logic-based approach. J Mol Biol 2013, 425:186-197.

31. Wolfe AJ: The acetate switch. Microbiol Mol Biol Rev 2005, 69:12-50.

32. Joshua GWP, Guthrie-Irons C, Karlyshev AV, Wren BW: Biofilm formation in Campylobacter jejuni. Microbiology 2006, 152:387-396.

33. Kalmokov M, Lanthier P, Tremblay T-L, Foss M, Lau PC, Sanders G, Austin J, Kelly J, Szymanski CM: Proteomic analysis of Campylobacter jejuni 11168 
biofilms reveals a role for the motility complex in biofilm formation. J Bacteriol 2006, 188:4312-4320.

34. Kantrowitz ER: Allostery and cooperativity in Escherichia coli aspartate carmamoyltransferase. Archiv Biochem Biophys 2012, 519:81-90.

35. Lipscomb WN, Kantrowitz ER: Structure and mechanisms of Escherichia coli aspartate carbamoyltransferase. Acc Chem Res 2012, 45:444-453.

36. Kleine LL, Monnet V, Pechoux C, Trubuil A: Role of bacterial peptidase $F$ inferred by statistical analysis and further experimental validation. HFSP J 2008, 2:29-41.

37. Newton KN, Courcelle CT, Courcelle J: UvrD participation in nucleotide excision repair is required for the recovery of DNA synthesis following UV-induced damage in Escherichia coli. J Nucl Acids 2012, 2012:271453.

38. Maples VF, Kushner SR: DNA repair in Escherichia coli: identification of the uvrD gene product. Proc Natl Acad Sci U S A 1982, 79:5616-5620.

39. Centore RC, Sandler SJ: UvrD limits the number and intensities of RecAGreen Fluorescent Protein structures in Escherichia coli K-12. J Bacteriol 2007, 189:2915-2920.

40. Ossana N, Mount DW: Mutations in uvrD induce the SOS response in Escherichia coli. J Bacteriol 1989, 171:303-307.

41. Fouts DE, Mongodin EF, Mandrell RE, Miller WG, Rasko DA, Ravel J, Brinkac LM, DeBoy RT, Parker CT, Daugherty SC, Durkin AS, Madupu R, Sullivan SA, Shetty JU, Ayodeji MA, Shvartsbeyn A, Schatz SC, Badger JH, Fraser CM, Nelson KE: Major structural differences and novel potential virulence mechanisms from the genomes of multiple Campylobacter species. PLoS Biol 2005, 3:e15.

42. Lertsethtakarn P, Ottemann KM, Hendrixson DR: Motility and chemotaxis in Campylobacter and Helicobacter. Ann Rev Microbiol 2011, 65:398-410.

43. Atack JM, Kelly DJ: Oxidative stress in Campylobacter jejuni: responses, resistance, and regulation. Future Microbiol 2009, 4:677-690.

44. Holmes K, Mulholland F, Pearson BM, Pin C, McNicholl-Kennedy J, Ketley JM, Wells JM: Campylobacter jejuni gene expression in response to iron limitatio and the role of Fur. Microbiology 2005, 151:243-257.

45. Miller CE, Williams PH, Ketley JM: Pumping iron: mechanisms for iron uptake by Campylobacter. Microbiology 2009, 155:3157-3165.

46. Miller CE, Rock JD, Ridley KA, Williams PH, Ketley JM: Utilization of lactoferrin-bound and transferrin-bound iron by Campylobacter jejuni. J Bacteriol 2008, 190:1900-1911.

47. Palyada K, Threadgill D, Stintzi A: Iron acquisition and regulation in Campylobacter jejuni. J Bacteriol 2004, 186:4714-4729.

48. Raphael $B H$, Joens $L A: F e o B$ is not required for ferrous iron uptake in Campylobacter jejuni. Can J Microbiol 2003, 49:727-731.

49. He Y, Frye JG, Strobaugh TP Jr, Chen C-Y: Analysis of Al-2/LuxS-dependent transcription in Campylobacter jejuni strain 81-176. Foodborne Pathog Dis 2008, 5:399-415.

50. van Vliet AHM, Baillon M-LA, Penn CW, Ketley JM: The iron-induced ferredoxin FdxA of Campylobacter jejuni is involved in aerotolerance. FEMS Microbiol Lett 2001, 196:189-193.

51. Kaakoush NO, Miller WG, de Reuse H, Mendz GL: Oxygen requirement and tolerance of Campylobacter jejuni. Res Microbiol 2007, 158:644-650.

52. Scott AE, Timms AR, Connerton PL, Loc Carrillo C, Adzfa Radzum K, Connerton IF: Genome dynamics of Campylobacter jejuni in response to bacteriophage predation. PLoS Pathog 2007, 3:e119.

53. Clark CG, Bryden L, Cuff W, Johnson PL, Jamieson F, Ciebin B, Wang G: Use of the Oxford multilocus sequence typing protocol and sequencing of the flagellin short variable region to characterize isolates from a large outbreak of waterborne Campylobacter sp. strains in Walkerton, Ontario, Canada. J Clin Microbiol 2005, 43:2080-2091.

54. Wiśniewski JR, Zougman A, Nagaraj N, Mann M: Universal sample preparation for proteome analysis. Nat Methods 2009, 6:359-362.

55. Vizcaino JA, Cote RG, Csordas A, Dianes JA, Fabregat A, Foster JM, Griss J, Alpi E, Birim M, Contell J, O'Kelly G, Schoenegger A, Ovelleiro D, PerezRiverol $Y$, Reisinger F, Rios $D$, Wang R, Hermjakob H: The Proteomics Identifications (PRIDE) database and associated tools: status in 2013. Nucleic Acids Res 2013, 41(D1):D1063-D1069. doi:10.1093/nar/gks1262. PubMed PMID:23203882

doi:10.1186/1471-2180-14-70

Cite this article as: Clark et al:: The CJIE1 prophage of Campylobacter jejuni affects protein expression in growth media with and without bile salts. BMC Microbiology 2014 14:70.

\section{Submit your next manuscript to BioMed Central and take full advantage of:}

- Convenient online submission

- Thorough peer review

- No space constraints or color figure charges

- Immediate publication on acceptance

- Inclusion in PubMed, CAS, Scopus and Google Scholar

- Research which is freely available for redistribution 